Human Mutation

WILEY

\title{
From Lowe syndrome to Dent disease: correlations between mutations of the OCRL1 gene and clinical and biochemical phenotypes
}

\begin{tabular}{|c|c|}
\hline Journal: & Human Mutation \\
\hline Manuscript ID: & humu-2010-0391.R1 \\
\hline Wiley - Manuscript type: & Research Article \\
\hline $\begin{array}{r}\text { Date Submitted by the } \\
\text { Author: }\end{array}$ & 27-Sep-2010 \\
\hline Complete List of Authors: & $\begin{array}{l}\text { Haifa, Hichri; CHU Grenoble, Biochimie et Genetique Moleculaire } \\
\text { Rendu, John; CHU Grenoble, Biochimie et Genetique Moleculaire } \\
\text { Monnier, Nicole; CHU Grenoble, Biochimie et Genetique Moleculaire } \\
\text { COUTTON, Charles; CHU Grenoble, Laboratoire de Genetique } \\
\text { Chromosomique } \\
\text { Dorseuil, Olivier; Institut Cochin, Dpt Genetique, Developpement et } \\
\text { Pathologie Moleculaire } \\
\text { Vargas Poussu, Rosa; HEGP, Dpt de Genetique } \\
\text { Baujat, Genevieve; Hopital Necker-Enfants Malades, Dpt de } \\
\text { Genetique } \\
\text { Blanchard, Anne; HEGP, Centre d'Investigation Clinique } \\
\text { Nobili, Francois; CHU Besancon, Nephrologie pediatrique } \\
\text { Ranchin, Bruno; Hospices Civil de Lyon, Centre de Référence des } \\
\text { Maladies Rénales Rares } \\
\text { Remesy, Michel; CHU Toulouse, Service de Nephrologie } \\
\text { Salomon, Remi; Hôpital Necker-Enfants Malades, Service de } \\
\text { Nephrologie Pediatrique } \\
\text { Satre, Veronique; CHU Grenoble, Laboratoire de Genetique } \\
\text { Chromosomique } \\
\text { LUNARDI, JOEL; Biochimie et Genetique Moleculaire, CHU Grenoble }\end{array}$ \\
\hline Key Words: & $\begin{array}{l}\text { Lowe syndrome, Dent disease, OCRL1, PiP2 homeostasis, endocytic } \\
\text { pathway }\end{array}$ \\
\hline
\end{tabular}

\section{SCHOLARONE ${ }^{\text {TM }}$ Manuscripts}


From Lowe syndrome to Dent disease: correlations between mutations of the OCRL1 gene and clinical and biochemical phenotypes

Haifa Hichri ${ }^{1}$, John Rendu ${ }^{1,2}$, Nicole Monnier ${ }^{1,2}$, Charles Coutton ${ }^{3}$, Olivier Dorseuil ${ }^{4}$, Rosa Vargas Poussou ${ }^{5}$, Geneviève Baujat ${ }^{6}$, Anne Blanchard ${ }^{7}$, François Nobili ${ }^{8}$, Bruno Ranchin ${ }^{9}$, Michel Remesy ${ }^{10}$, Rémi Salomon ${ }^{11}$, Véronique Satre ${ }^{3}$, Joel Lunardi ${ }^{1,2, *}$

${ }^{1}$ CHU Grenoble, Laboratoire de Biochimie et Génétique Moléculaire, Grenoble, F-38043

${ }^{2}$ INSERM U836, Grenoble Institut des Neurosciences, Grenoble, F-38043

${ }^{3}$ CHU Grenoble, Laboratoire de Génétique Chromosomique, Grenoble, F-38043

${ }^{4}$ Institut Cochin, Département de Génétique, Développement et Pathologie Moléculaire, INSERM U567-CNRS UMR8104-Université Paris V, Paris, F-75014

${ }^{5}$ Hôpital Européen Georges Pompidou, Département de Génétique et Inserm U 970, Paris, F-75015

${ }^{6}$ Hôpital Necker-Enfants Malades, Département de Génétique, Paris F-75015

${ }^{7}$ Hôpital Européen Georges Pompidou, Centre d'Investigation Clinique, Paris, F-75015

${ }^{8}$ CHU Besançon, Néphrologie Pédiatrique, Besançon, F-25030

${ }^{9}$ Hôpital Femme, Mère, Enfant, Hospices Civils de Lyon, Centre de Référence des Maladies Rénales Rares, Bron, F-69000

${ }^{10}$ CHU Toulouse, Hôpital des Enfants, Service de Néphrologie, Toulouse, F-31059

${ }^{11}$ Hôpital Necker-Enfants Malades, Centre de Référence des Maladies Rénales Héréditaires de l'Enfant et de l'Adulte; Paris, F-75015

corresponding author * :

Joel Lunardi

Laboratoire de Biochimie et Génétique Moléculaire, Inserm U836

CHU Grenoble BP217X

38043 Grenoble Cedex

France

E-mail: jlunardi@chu-grenoble.fr 


\begin{abstract}
Mutations of OCRL1 are associated with both the oculocerebrorenal syndrome Lowe, a multi-systemic and Dent-2 disease, a renal tubulopathy. We have identified a mutation in 130 Lowe syndrome families and 6 affected by Dent- 2 disease with 51 of these mutations being novel. No founding effect was evidenced for recurrent mutations. Two mutations initially reported as causing Dent-2 disease were identified in patients, including two brothers, presenting with Lowe syndrome thus extending the clinical variability of OCRL1 mutations. mRNA levels, protein content and $\mathrm{PiP}_{2}$-ase activities were analyzed in patient's fibroblasts. Although mRNA levels were normal in cells harbouring a missense mutation, the OCRL1 content was markedly lowered suggesting that enzymatic deficiency resulted mainly from protein degradation rather than a catalytic inactivation as usually reported. Analysis of a splicing mutation that led to the elimination of the initiation codon evidenced the presence of shortened forms of OCRL1 that might result from the use of alternative initiation codons. The specific mapping of the frameshift and nonsense mutations, exclusively identified in exons 17 and exons 8-23 respectively for Dent disease and Lowe syndrome together with the possible use of alternative initiation codons might be related to their clinical expression i.e. Lowe syndrome or Dent-2 disease.
\end{abstract}

\title{
KEYWORDS :
}

OCRL1 - Lowe syndrome - Dent 2 disease - Phosphatidylinositol 4,5 biphosphate 


\section{INTRODUCTION}

\section{Lowe syndrome}

The oculocerebrorenal syndrome of Lowe (OCRL [MIM\#309000]) is a rare X-linked multisystem disorder presenting with major abnormalities in the eyes, the kidneys and the central nervous system [Lowe et al., 1952; Loi, 2006]. OCRL is a rare disease with a prevalence estimated between 1 and 2 boys per million people. Ocular abnormalities include a constant prenatal development of cataracts and frequent associated signs such as glaucoma, microphthalmos, decreased visual acuity and corneal keloid formation. Neonatal hypotonia, intellectual impairment and areflexia are also cardinal features. The majority of patients have a cognitive delay and behavioural troubles including temper tantrums and aggressiveness are frequently noted. Brain magnetic resonance imaging (MRI) may show periventricular cystic lesions [Schneider et al., 2001; Loi, 2006]. Fanconi syndrome, a generalized impairment of the proximal tubular cells functions, is a major feature.

Onset of the tubular dysfunction can vary between patients and the severity tends to worsen with age. Low molecular weight proteinuria (LWMP) is invariably present and aminoaciduria, hypercalciuria and bicarbonaturia are frequently included. Progressive glomerular dysfunction leads usually to renal failure. Skeletal muscle abnormalities may develop as secondary consequences of hypotonia or renal dysfunction. Nontender joint swelling and subcutaneous nodules are also frequently described in affected patients and may reflect a primary abnormality of connective tissue growth. Lowe syndrome results from mutations of the OCRL1 gene (MIM \#300535) that encodes a phosphatidyl inositol 4,5 biphosphate $\left(\mathrm{PI}(4,5) \mathrm{P}_{2}\right)$ phosphatase.

\section{Dent disease}


Dent's disease (Dent-1, MIM\#300009), is a X-linked proximal renal tubulopathy, characterized by LWMP, hypercalciuria and progressive renal insufficiency. In addition, other features of proximal tubular dysfunction such as glycosuria, aminoaciduria, phosphaturia, uricosuria or complete Fanconi syndrome may also be present [Dent and Friedman, 1964; Thakker, 2000]. Except for rickets noted in some patients; no extra-renal manifestations of the disease have been reported.

Mutations in the CLCN5 gene (MIM \#300008) encoding the renal voltagegated chloride channel CLC-5 have been reported in $60 \%$ of patients with Dent's disease [Lloyd et al., 1996, Hoopes et al., 2004]. ClC-5 is mainly localized in subapical endosomes of epithelial kidney cells and contributes to the acidification of intra-endosomal compartments and participates in membrane recycling in the proximal tubule [Devuyst et al., 1999; Piwon et al., 2000]. A recent study showed that mutations in the OCRL1 gene can lead to a Dent-like phenotype (Dent-2 disease, DD-2, MIM \#300555) that can present as a clinical intermediate between Lowe syndrome and Dent disease [Hoopes et al., 2005; Bökenkamp et al., 2009]. Nevertheless, DD-2 patients harbouring an OCRL1 mutation displayed comparable decrease in PI(4,5)P2ase activity and OCRL1 content to those reported for patients affected by Lowe syndrome [Hoopes et al., 2005; this study].

\section{OCRL1}

OCRL1 is a type II inositol polyphosphate 5-phosphatase that participates into the Lowe, 2005]. OCRL1 has been originally localized to the Trans-Golgi Network and to lysosomes [Olivos-Glander et al., 1995; Dressman et al., 2000; Ungewickell et al., 2004] and more recently to endosomes [Choudury et al., 2005; Hyvola et al., 2006; Erdmann et al., 2007]. Abnormalities in the actin cytoskeleton have been demonstrated in Lowe fibroblasts 
[Suchy and Nussbaum, 2002] and OCRL1 was recently proposed to play a role in regulating membrane trafficking and actin dynamics [Lowe, 2005; Faucherre et al, 2005].

The OCRL1 gene spans 52278 bp on chromosome Xq24.26 [ENSG00000122126] and contains 24 exons with exon 18 a as an alternatively spliced exon mostly expressed in brain [Attree et al., 1992; Nussbaum et al., 1997]. The ATG start codon was initially assigned to exon 2 [Attree et al, 1992], however recent reports mapped the initiation codon in exon 1 [Hyvola et al., 2006; Erdmann et al, 2007; Mao et al., 2009]. Accordingly the 5156 bp cDNA (NM_000276) encodes a protein monomer of 901 amino-acids (MW = 103226 kDa).

This paper reports 51 novel mutations of the OCRL1 gene associated either with Lowe syndrome or Dent-2. Correlations between the mutations and their expression at the mRNA, functional and protein levels will be discussed in regard to their clinical expression. Based on these data, putative mechanisms to explain how mutations of the OCRL1 protein express as heterogeneous clinical entities will be discussed.

\section{MATERIAL AND METHODS}

\section{Patients and samples}

A panel of 175 non-related families addressed to the laboratory for suspicion of Lowe syndrome has been investigated. Among the male patients addressed for suspicion of Lowe syndrome, 124 index cases presented with full criteria of Lowe syndrome. 15 mothers of deceased children likely to be affected by Lowe syndrome were also investigated for mutations in the OCRL1 gene. French clinical centres addressed 58\% of the families with the remaining families originating from Europe (18\%), Middle-East (5\%), North-America (5\%), Asia (6\%) and Australia (3\%). 
41 patients affected by Dent's disease were additionally included in the study. All patients originated from France, they did not show cataract or noticed neurological troubles and did not harbour mutations in the CLCN5 gene.

Blood samples and, whenever possible, fibroblasts, were obtained from the affected patients and/or from their relatives. An informed consent allowing genetic studies was obtained from all patients included in the study.

\section{Mutation detection}

Genomic DNA was isolated using standard procedures. The 24 exons of the OCRL1 gene were amplified from genomic DNA as described previously [Monnier et al., 2000]. For mutational analysis, PCR-amplified DNA products were subjected to direct automated sequencing on an ABI 3130 DNA Analyser (Life Technologies, Carlsbad, CA, USA).

Alternatively RNA was extracted from 2-5 $10^{6}$ fibroblast cells using the Trizol ${ }^{\circledR}$ reagent (Life Technologies, Carlsbad, CA, USA). RNA was dissolved in $50 \mu$ l of RNAsefree water. Reverse transcription was performed by using $0.2 \mathrm{mg}$ of total RNA at $48^{\circ} \mathrm{c}$ for 60 minutes with $50 \mathrm{U}$ of Expand Reverse Transcriptase (Roche, Basel, Switzerland) and in the presence of oligo-dT and the following specific primer (5'AACTTTGGCTTGGCAATATAAGTC). The resulting cDNA was then amplified and sequenced as previously described. ${ }^{24}$ Mutations responsible for aberrant sized transcripts were characterized by direct sequencing of the corresponding exon and intron-exon junctions.

Mutation assignment was based on the cDNA sequence (Genbank \# NM_000276) using the first coding ATG of exon 1 as initiation codon according to international guidelines for description of sequences variants (http://www.hgvs.org/mutnomen). This resulted in an in frame addition of 51 nucleotides at the $5^{\prime}$ end of the cDNA and of 17 amino acids at the $\mathrm{N}$ terminal end of the protein in comparison with the initial nomenclature [Attree et al., 1992]. 
None of the novel variants identified in this study were found after screening of 200 chromosomes from the general population. Genomic rearrangements were evidenced using data obtained from PCR screening or MLPA analysis in probands. In families harbouring a genomic rearrangement, the carrier status of mothers was determined using a homemade MLPA $®$ assay (MRC Holland, Amsterdam, The Netherlands) [Coutton et al, 2010].

\section{Quantitative transcript analysis}

Quantitative PCR was performed using $100 \mathrm{ng}$ of cDNA in a final volume of $25 \mu \mathrm{l}$ and specific primers for the OCRL1 gene (F-5'-CGAGCTGTATCAGCGATGTC; R-5'GGAGGCCTCAGGAGAAGACT) and the GAPDH gene used as control (F-5'CATCAAGAAGGTGGTGAAGC; R-5'- GAGCTTGACAAAGTGGTCGT). The OCRL1 primers allowed the amplification of a 197 bp fragment spanning exon 21 to 23. Duplicated samples were PCR were run on a iQ Cycler apparatus in presence of the iQ SYBR Green Supermix containing $500 \mathrm{nM}$ primers (Biorad, Hercules, CA, USA).

\section{Enzymatic assay for $\mathrm{PI}(4,5) \mathrm{P}_{2}$ phosphatase activity}

Activity was assayed as described previously on cell extracts prepared by freezethawing of fibroblasts obtained from affected and non affected patients except that each assay included $50 \mu \mathrm{g}$ of fibroblast protein and that quantification was performed by direct analysis of the TLC plates using a Beta Imager 2000 (Biospace, Paris, France) [Suchy et al., 1995; Satre et al., 1999].

\section{Western blot analysis}

For western blot analysis, aliquots of cell extracts ( $25 \mu \mathrm{g}$ of protein) were resolved by an $8 \%$ SDS-polyacrylamide gel electrophoresis and electro-blotted onto Immobilon P transfer 
membrane (Millipore, Billerica, MA, USA). OCRL1 was revealed using polyclonal antibodies raised in rabbit against the N-terminal region (amino-acids 18-217) and a peroxidase-labelled mouse anti-rabbit detection system. As control we used the signals obtained using polyclonal antibodies raised against the $\beta$-subunit of the mitochondrial ATPase. The amount of OCRL1 present in each sample was determined by quantitative western blot analysis using a ChemiDoc XRS apparatus and the Quantity One ${ }^{\circledR}$ software (BioRad, Hercules, CA, USA), after correction of protein loading by Coomassie blue staining.

\section{Results}

\section{Mutation analysis}

We have identified a mutation in the OCRL1 gene in 130 out of the 175 families included for Lowe's syndrome and in 6 out of the 41 Dent disease families. 51 of these mutations were novel (Table 1) with four of them identified in patients affected by Dent-2 disease. Extensive genomic and cDNA sequencing analysis led to the correction of boundaries of exons $8,9,11,12,13,14$ in reference to those reported in the Lowe Syndrome Mutation Database ${ }^{28}$ and to the use of a cDNA numbering based on the use of initiation codon in exon 1 (Supplementary Table S1).

Near to 200 mutations have been identified so far in the OCRL1 gene in association with Lowe syndrome or Dent-2 disease (Supplementary Table S2). Frameshift, splicing or non-sense mutations leading to a premature termination of the protein represented $63 \%$ of the mutations whereas missense mutations and genomic deletion accounted respectively for $33 \%$ and $4 \%$ of the molecular variations. No noticeable differences in this distribution were noticed when comparing Lowe syndrome or Dent-2 Disease. 33 recurrent mutations were identified and accounted for the disease in $41 \%$ of the genotyped families. 17 mutations have been 
reported in more than 3 families ( $n=3$ : p.Ile274Thr, p.Arg318Cys, p.Arg334Stop, p.Gln388Stop, p.Arg822Stop; n=4: c.940-11G>A, p.Gly421Glu, p.Arg500Stop, p.Arg541Stop, c.1694_1695insCCTT, c.2360_2361delTG, p.Arg844Stop; $n=5$ : p.Arg663Stop, p.Arg695Stop , p.Arg810Stop; n=8: p.Arg500Gln; n=10: c.2581G>A). As it could be inferred from data presented in supplementary Table S2, none of these mutations appeared to be population specific.

Genetic investigation of 98 mothers of patients affected by Lowe syndrome showed the occurrence of a de novo mutation in 36 cases $(37.2 \%)$ whereas 3 cases of mosaicism were characterized in our panel of genotyped families indicating that, although not frequent, mosaicism must be taken in account for genetic counselling.

As shown in Figure 1, 53 out of the 66 missense mutations reported to date mapped to the $\mathrm{PI}(4,5) \mathrm{P}_{2}$ phosphatase domain spanning exons 9-15. They involved amino-acids defined as major determinants for specificity of the inositol polyphosphate 5-phosphatase activity [Whisstock et al., 2000; Tsujishita et al., 2001]. The remaining missense mutations were identified in the C-terminal ASH-RhoGAP-like domain spanning exons 16 to 23 [Peck et al., 2002; Faucherre et al., 2003, Choudhury et al., 2005; Hyvola et al., 2006; Erdmann et al., 2007] and involved amino acids located in well conserved domains (supplementary Figure S1). Noticeably, no missense mutations have been identified so far in exons 1 to 8 .

Frameshift mutations or nonsense mutations leading to premature termination of the protein have been characterized in all exons but exons 2 and 3 (Fig 1). While nine substitutions affected directly the consensus acceptor or donor sites at the exon-intron junctions, seven additional intronic mutations induced abnormal splicing: c.40-14A>G, c. $238+4701 \mathrm{G}>\mathrm{A}, \quad$ c. $940-11 \mathrm{G}>\mathrm{A}, \quad$ c. $1467-3 \mathrm{C}>\mathrm{G}, \quad$ c. $1879+5 \mathrm{G}>\mathrm{A}, \quad$ c.1880-5del16, c.2469+2_6delinsA, c.2581+4A>G. Transcript analysis showed that 3 substitutions affecting the last nucleotide of exons 9,14 and 22 : c.824G $>$ C, c. $1466 \mathrm{G}>\mathrm{A}, \mathrm{c} .2581 \mathrm{G}>\mathrm{A}$ affected the 
splicing. Thus, the p.Gly275Ala, p.Ser489Asn, p.Ala861Thr mutations, initially reported as missense mutations [Kawano et al., 1998; Monnier et al., 2000] led thus primarily to a premature termination of the protein.

Noticeably, while frameshift and nonsense mutations associated with Lowe syndrome concentrated in exons exons 8 to 23 , all frameshift and nonsense mutations causative of Dent 2 disease have been characterized so far only in the first seven exons.

\section{Functional expression of mutations}

mRNA expression

As shown in Figure 2 no significant differences in the level of mRNA expression of the OCRL1 gene could be evidenced in patients harbouring a missense mutation when compared to controls. At difference, patients harbouring stop, frameshift or splicing mutations showed a very low mRNA content that indicated either a decreased transcription or more likely a mRNA instability resulting from a non sense mediated decay mechanism. No difference was observed between patients affected by Lowe syndrome or Dent-2 disease. Noticeably, one patient harbouring a c.[40-14A $>$ G] splicing mutation showed a normal amount of mRNA (Figure 2, arrow). As shown in panel A of the figure 3, the c.40-14A>G mutation resulted in the production of two abnormal transcripts. Sequencing analysis showed that whereas both transcripts could be amplified and quantified, they both lacked the 3 ' end of exon 1 that contains the ATG initiation codon (supplementary Fig S2).

PIP2ase activity 
PI $(4,5) \mathrm{P}_{2}$ phosphatase activity was measured in 12 patients harbouring a missense mutation and in 11 patients harbouring a nonsense or a frameshift mutation that led to a premature termination of the protein. As presented in table 2 the enzymatic activities measured in patients with either a missense mutation or a mutation leading to a premature termination of the protein showed a mean inhibition of $85-90 \%$ when compared to PI $(4,5) \mathrm{P}_{2}$ phosphatase activity determined in fibroblasts originating either from healthy individuals or from patients addressed for a suspicion of Lowe syndrome and for whom no mutation had been identified in the $O C R L 1$ gene. No significant differences between the residual activities measured in fibroblasts harbouring a missense mutation and those harbouring a nonsense or frameshift mutation were evidenced. Likewise no differences of PI $(4,5) \mathrm{P}_{2}$ phosphatase activities could be evidenced between Lowe syndrome or Dent-2 patients (not shown). Residual activities measured in mutant fibroblasts were likely to correspond to non specific hydrolysis of PI $(4,5) \mathrm{P}_{2}$ by other inositol polyphosphate phosphatases present in fibroblasts since they were also determined in cells fully devoid of OCRL1 as a consequence of a genomic deletion of the OCRL1 gene [Lin et al., 1997; Monnier et al., 2000; this paper].

\section{OCRL1 protein analysis}

The amount of OCRL1 was estimated in total cell extracts using either the total protein amount or the $\beta$-ATPase signals for normalisation. As shown in Figure 4, patients harbouring a missense mutation in the OCRL1 gene (lanes 2-6) had a markedly reduced content of OCRL1 when compared to controls (lanes 1, 7, 8, 12). Two bands were revealed by antibodies, the upper band at $\approx 105 \mathrm{kDa}$ corresponds to the native OCRL1 while the lower band at $\approx 75 \mathrm{kDa}$ corresponds to a proteolytic product [Lichter-Konecki et al., 2006]. As expected, cells harbouring stop and frameshift mutations and characterized by a low mRNA content showed an almost complete absence of OCRL1 (lanes 9,10,11). For quantification 
studies of OCRL1 presented in table 3, both bands were taken in account. Unexpectedly, most missense mutations resulted in a drastic decrease of the OCRL1 content although their mRNA content was unaffected (Fig 2). The decrease in OCRL1 was observed whether missense mutation mapped to the central phosphatase domain or to the C-terminal Rho-Gap domain (Fig 4). This indicated that missense mutations not only could affect the catalytic properties of OCRL1 but also could affect the stability of the protein. Noticeably, expression of the c.40$14 \mathrm{~A}>\mathrm{G}$ resulted in the presence of a protein doublet at $\approx 80 \mathrm{kDa}$ with no detectable bands at 100 or $75 \mathrm{kDa}$ (Fig 3, panel B, lane 2).

\section{Clinical expression of mutations}

All but two of the 124 male patients that presented with classical features of the disease i.e. congenital bilateral cataract, central nervous system symptoms and kidney troubles harboured a mutation in the OCRL1 gene. However as no cDNA analysis could be performed for these two patients, we cannot exclude the presence of a mutation not detected by genomic sequencing. At contrast, no mutation in the OCRL1 gene was identified in the 36 additional male patients presenting with an incomplete panel of oculocerebrorenal symptoms although highly suggestive of Lowe syndrome. When tested $\mathrm{PI}(4,5) \mathrm{P}_{2}$ phosphatase activity also excluded the diagnosis of Lowe syndrome in these patients.

6 out of the 41 patients included on the basis of diagnosis of a Dent disease not associated to the $C L C 5$ gene carried a mutation of the $O C R L 1$ gene. None of these 6 patients had ocular or CNS symptoms.

A few mutations that mapped to the same amino acid or to amino acids located at close vicinity were identified in patients addressed either for diagnosis of Lowe syndrome or Dent disease (Table 4). The p.Ile274Thr initially described in a patient presenting with the 
phenotype of Dent disease [Utsch et al., 2006] was identified in two families, one presenting with a classical Dent disease and one diagnosed as a Lowe syndrome family in which the two affected brothers had mental retardation and developmental with one of them having a congenital cataract. Likewise, the p.Arg318Cys mutation previously reported in 2 families with Dent disease [Hoopes et al., 2005; Sekine et al., 2007] was identified in a patient presenting with Dent disease and in another patient initially diagnosed as Lowe syndrome patient on the basis of renal and CNS symptoms although ocular symptoms at $24 \mathrm{y}$ of age were restricted to a severe myopia. Three mutations mapped to amino acids closely located in the Rho-GAP domain i.e. p.Ala797Pro, p.Pro799Leu and p.Pro801Leu. While all the three mutations were associated with proximal tubulopathy, only two of them (p.Ala797Pro and p.Pro801Leu) were associated with congenital cataract and SNC symptoms, typical features of the Lowe syndrome.

\section{CONCLUSIONS AND DISCUSSION}

A major consequence of mutations affecting the OCRL1 gene was the loss of $\mathrm{PI}(4,5) \mathrm{P}_{2}$ ase activity regardless of the Lowe or Dent-2 clinical phenotypes associated with mutations in patients and regardless of the pathogenic mechanisms.

Nonsense mutations, genomic deletions, frameshift or splicing mutations leading to the occurrence of a premature termination codon represent $2 / 3$ of the OCRL1 mutations identified to date. Expression studies of these mutations indicated that all but one of the mutations tested resulted in an almost complete absence of mRNA and protein (Fig. 2 and table 3).

Interestingly, the splicing c.40-14G>A mutation allowed an apparently normal quantitative production of mRNA. However and as shown in Fig. 3 (panel A) the mutation led 
to the synthesis of two abnormal transcripts lacking the normal initiation codon in exon 1 (see supplementary Fig. S2). As shown in panel B of Fig. 3 two peptides with a molecular weight close to $80 \mathrm{kDa}$ were evidenced in fibroblasts harbouring the c.40-14 $\mathrm{A}>\mathrm{G}$ mutation. Based on bioinformatics analyses, it has been recently proposed that a differential splicing of the OCRL1 gene associated with the possible use of an alternative initiation of translation in exon 8 that would allow the synthesis of a shortened OCRL1 might occur in different tissues and at different developmental stages [Schrimpton et al., 2009]. Remarkably, frameshift and nonsense mutations associated so far with Dent-2 disease were exclusively identified in the first 7 exons of the OCRL1 gene while all frameshift and nonsense mutations causing Lowe syndrome mapped to exons 8-23 (Fig 1). There are only three methionyl residues in the sequence spanning exon 3 to 10 at position 158, 187 and 206, respectively in exons 7 and 8, that will keep the OCRL1 reading frame. As suggested by Schrimpton [Schrimpton et al., 2009], use of these methionyl residues as alternative initiation codons will allow the synthesis of $85.425 \mathrm{kDa}, 82.159 \mathrm{kDa}$ and $79.976 \mathrm{kDa}$ peptides respectively, molecular weights compatibles with the observed bands at $\approx 80 \mathrm{kDa}$ in Fig 3. Such proteins will lack the PH domain and a major clathrin binding site [Mao et al., 2009] and are likely to display modified interactions with membranes and other proteins.

While most missense mutations mapped to the phosphatase domain of OCRL1 spanning exons 9-15, 14 missense mutations or in-frame deletion have been identified in the

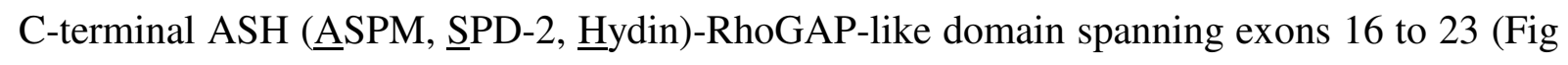
1). Eight mutations mapped to the ASH/Rab binding domain spanning exons 17-19 (amino acids 539-752) close to residues that have been shown to modulate Rab binding and targeting of OCRL1 to Golgi and endosomes [Hyvola et al., 2006]. The six missense mutations in exons 20-23 affected amino acids that mapped to a region in close interaction with the ASH domain [Erdman et al., 2007]. Mutations in exon 21 clustered to a domain showing significant 
homologies with GAP related proteins (Supplementary Fig S1). Although interaction with Rac 1 a member of the Rho family has been reported [Erdman et al., 2007] and low Rac GAP activity measured in vitro [Faucherre et al., 2003], whether OCRL1 functions as a GAP in vivo is still debated [Lowe, 2005]. Expression studies of the p.I768N and p.A797P mutations in COS7 cells suggested that the Rho-GAP like domain is important for the enzymatic activity of OCRL1 while being catalytically inactive by itself and showed that this domain could also interact with small G-proteins of the Arf family [Lichter-Konecki et al., 2006]. Therefore and as suggested by their effect on activity and OCRL1 content, these last two residues might play a critical role for the folding of the protein. The ASH-RhoGAP-like domain has been recently shown to interact with the Rab5 effector APPL1 [Erdmann et al., 2007; McCrea et al., 2008] and with Ses1 and Ses2, two closely related endocytic proteins [Swan et al., 2010]. Isothermal titration calorimetry studies performed using peptides corresponding to the interacting domains of Ses1 and APPL1 with OCRL1 suggested that binding of Ses and APPL1 are mutually exclusive and abolished by the same mutations at positions 591, 634, 799, 801 in the ASH-RhoGAP-like domain that also disrupt APPL1 binding. This suggested that Lowe syndrome and Dent disease might result from perturbations at multiple sites within the endocytic pathway [Swan et al., 2010]. Noticeably, most variants affected amino acids conserved among OCRL1 species and INPP5B but much less conserved among other polyphosphate phosphatases. This may suggest that interaction with Rab proteins is a specific feature of OCRL1 and INPP5B.

The decrease of the $\mathrm{PI}(4,5) \mathrm{P}_{2}$ ase activity in mutant cells harbouring a missense mutation was usually associated with a deleterious effect of the missense mutations on phosphatase activity, whether they mapped to the catalytic $\mathrm{PI}(4,5) \mathrm{P}_{2}$ ase domain or to the RhoGAP domain [Lin et al., 1997., Hyvola et al., 2006., Schrimpton et al., 2009]. However and as illustrated in Fig. 4 and Table 3, the consequence of missense mutations is mostly a decrease 
of the amount of OCRL1 present in the cell. This is likely to result from an abnormal processing of the protein since OCRL1 mRNA levels were normal in the cells harbouring these missense mutations (Fig. 2). The protein degradation might be the consequence of the activation of endoplasmic reticulum-associated degradation (ERAD) or of tunfolded protein response (UPR) as an answer to the accumulation of unfolded or misfolded mutant OCRL1 in the endoplasmic reticulum [Schröder and Kaufman., 2005]. Conclusions of functional studies based on expression mutant OCRL1 in cellular models must thus take in account protein degradation processes when analysing the physiological relevance of the different mutations. Nevertheless, a small amount (20-30\%) of OCRL1 was detected in a few mutant cells although $\mathrm{PI}(4,5) \mathrm{P}_{2}$ ase activity was almost totally absent. In these situations, the overall decrease of $\mathrm{PI}(4,5) \mathrm{P}_{2}$ ase activity is likely to result from two processes: a decrease of the amount of OCRL1 through protein degradation and a catalytic inactivation. A few missense mutations e.g. p.Phe242Ser, p.Ala797Pro resulted in the presence of both a small amount of protein and a residual $\mathrm{PiP}_{2}$ ase activity. Noticeably, although the Lowe patients harbouring these mutations presented with classical eye and kidney features, their neurological symptoms were less severe and their degree of mental retardation was moderate. This may reflect a differential dependence of tissues or of developmental stages toward PI(4,5) $\mathrm{P}_{2}$ homeostasis. Differences in clinical expression that were observed between patients harbouring different mutations might thus reflect variability in protein synthesis and/or catalytic properties in the different tissues depending on the nature of the mutation beside variability of the individual genetic background.

Mutations of the OCRL1 gene have been associated with two distinct clinical phenotypes i.e. Lowe syndrome and Dent disease. Although apparently undistinguishable from the Dent phenotype associated to the CLCN5 gene, Dent phenotype associated with OCRL1 mutations has been referred as Dent-2 disease to specify the genetic cause of the 
disease and may represent a mild variant of Lowe syndrome [Bökenkamp et al., 2009].

Accordingly, it has been proposed that a phenotypic continuum exists between Dent- 2 disease and Lowe syndrome. This continuum was not only observed between patients harbouring different OCRL1 mutations but also occurred between patients harbouring the same mutation as presented in table 4. Clinical phenotypes range from patients affected by severe Lowe syndrome with typical ocular, neurological and renal features to Dent-2 patients presenting only with renal impairment and comprise atypical forms of Lowe syndrome presenting with incomplete eye symptoms or moderate neurological troubles. Presence of a residual $\mathrm{PI}(4,5) \mathrm{P}_{2}$ ase activity has been documented during this study in patients presenting usually with a moderate clinical expression. However, it must be noted that ocular and neurological symptoms were documented even in Lowe patients showing a residual $\mathrm{PI}(4,5) \mathrm{P}_{2}$ ase activity up to $20 \%$ of the normal values in their fibroblasts. On the other hand, it must be kept in mind that mild and severe presentations of Lowe syndrome together with pure real forms of Dent disease were associated with a complete loss of the OCRL1 enzymatic activity. A possible explanation of this clinical variability might be the presence of modifying factors (compensatory phosphatases, interacting proteins...) whose expression will depend on the genetic background of the different patients. The main clinical difference observed between two brothers presenting with a Lowe syndrome and harbouring the same p.Ile274Thr mutation e.g. a documented unilateral cataract for the youngest and no signs of cataract for the eldest one would thus likely result from such modifying factors. Along this line we have investigated a possible role of INPP5B, a phosphatase. No significant variations in the INPP5B content could be evidenced when comparing fibroblast extracts originating from healthy controls or patients affected either by Lowe syndrome or Dent-2 disease. This was in agreement with our data showing that no significant differences of the PiP2-ase activity could be evidenced between Lowe syndrome and Dent-2 disease patients (table 2). 
The report of truncated forms of OCRL1 that might result from the use of alternative initiation codons open also new perspectives to explain clinical variability associated with OCRL1 mutations. However these investigations were performed on skin fibroblasts and using antibodies that may not recognize all forms of truncated or alternatively spliced OCRL1. It will be very important to extend these studies to other cell types that are more affected by the disease e.g. renal and ocular cells and to use a larger panel of antibodies directed against different domains of the protein in order to gain new insights regarding the differential pathological mechanisms leading to the different clinical phenotypes.

\section{ACKNOWLEDGMENTS}

We thank all family members for their invaluable contribution to this study. This work was supported in part by grants from the Agence National de la Recherche, GIS-Maladies Rares, Association du Syndrome de Lowe and Fondation Daniel Ducoin (to J.L.). RV-P and AB are supported by EUNEFRON (FP7, GA\#201590) programs of the European Community.

\section{REFERENCES}

Addis M, Loi M, Lepiani C, Cau M, and Melis MA. (2004). OCRL mutation analysis in Italian patients with Lowe syndrome. Hum. Mutation. 23, 524-525.

Addis M, Meloni C, Congiu R, Santaniello S, Emma F, Zuffardi O, Ciccone R, Cao A, Melis MA, Cau M. 2007. A novel interstitial deletion in Xq25, identified by array-CGH in a patient with Lowe syndrome. Eur J Med Genet 50:79-84. 
Attree O, Olivos I, Okabe I, Bailey C, Nelson D, Lewis R, McInnes RR, Nussbaum R. 1992. The Lowe oculocerebrorenal syndrome gene encodes a novel protein highly homologous to inositol polyphosphate-5-phosphatase. Nature 358:239-242.

Böckenhauer D, Bokenkamp A, Van't Hoff W, Levchenko E, Kist-van Holte JE, Tasic V, Ludwig M. 2008. Renal phenotype in Lowe syndrome: a selective proximal tubular dysfunction. Clin J Am Soc Nephrol 3:1430-1436.

Bökenkamp A, Böckenhauer D, Cheong HI, Hoppe B, Tasic V, Unwin R, Ludwig M. 2009. Dent-2 disease: a mild variant of Lowe syndrome. J Pediatr 155:94-99.

Chabaa L, Monnier N, Dahri S, Jorio M, Lunardi J, Chabraoui L. 2006.Oculo-cerebro-renal Lowe syndrome: clinical, biochemical and molecular studies in a Moroccan patient. Ann Biol Clin 64:53-59.

Chou YY, Chao SC, Chiou YY, Lin SJ. 2005. Identification of OCRL1 mutations in two Taiwanese Lowe syndrome patients. Acta Paediatr Taiwan 46:226-229.

Choudury R, Diao A, Zhang F, Eisenberg E, Saint-Pol A, Williams C, Konstantakopoulos A, Lucocq J, Johannes L, Rabouille C, Greene LE, Lowe M. 2005. Lowe syndrome protein OCRL1 interacts with clathrin and regulates protein trafficking between endosomes and the trans-Golgi network. Mol Biol Cell 16:3467-3479.

Coutton C, Monnier N, Rendu J, Lunardi, J. 2010. Development of a multiplex ligationdependent probe amplification (MLPA) assay for quantification of the OCRL1 gene. Clin Biochem 43:609-614.

Dent CE, Friedman M. 1964. Hypercalciuric rickets associted with renal tubular damage. Arch Dis Child 39:240-249.

Dewuyst O, Christie PT, Courtoy PJ, Beauwens R, Thakker RV. 1999. Intra-renal and subcellular distribution of the human chloride channel, $\mathrm{ClC}-5$, reveals a pathophysiological basis for Dent's disease. Hum Mol Genet 8:247-257. 
Dressman MA, Olivos-Glander IM, Nussbaum RL, Suchy SF. 2000. Ocrl1, a

PtdIns(4,5)P(2)5-phosphatase, is localized to the trans-Golgi network of fibroblasts and epithelial cells. J Histochem Cytochem 48:179-190.

Erdmann KS, Mao Y, McCrea HJ, Zoncu, R, Lee S, Paradise S, Modregger J, Biemesderfer

D, Toomre D, De Camilli P. 2007. A role of the Lowe syndrome protein OCRL in early steps of the endocytic pathway. Dev Cell 13:377-390.

Faucherre A, Desbois P, Satre V, Lunardi J, Dorseuil O, Gacon G. 2003. Lowe syndrome protein OCRL1 interacts with Rac GTPase in the trans-Golgi network. Hum Mol Genet $12: 2449-2456$.

Faucherre A, Desbois P, Nagao F, Satre V, Lunardi J, Gacon G, Dorseuil O. 2005. Lowe syndrome protein OCRL1 is translocated to membrane ruffles upon Rac GTPase activation: a new perspective on Lowe syndrome pathophysiology. Hum Mol Genet 14:1441-1448.

Gropman A, Levin S, Yao L, Suchy S, Sabnis S, Hadley D, Nussbaum R. 2000. Unusual renal features of Lowe syndrome in a mildly affected boy. Am J Med Genet 95:461-466.

Hoopes RR Jr, Raja KM, Koich A, Huebber P, Reid R, Knohl SJ, Scheinman SJ. 2004.

Evidence for genetic heterogeneity in Dent's disease. Kidney Int 65:1615-1620.

Hoopes RR Jr, Shrimpton AE, Knohl SJ, Hueber P, Hoppe B, Matyus J, Simkles A, Tasic V, Toenshoff B, Suchy SF, Nussbaum RL, Scheinman SJ. 2005. Dent Disease with mutations in OCRL1. Am J Hum Genet 76:260-267.

Hyvola N, Diao A, McKenzie E, Skippen A, Cockcroft S, Lowe M. 2006. Membrane targeting and activation of the Lowe syndrome protein OCRL1 by rab GTPases. EMBO J 25:3750-3761. 
Kawano T, Indo Y, Nakazato H, Shimadzu M, Matsuda I. 1998. Oculocerebrorenal syndrome of Lowe: three mutations in the OCRL1 gene derived from three patients with different phenotypes. Am J Med Genet 77: 348-355.

Keilhauer CN, Gal A, Sold JE, Zimmermann J, Netzer KO, Schramm L. 2007. Clinical findings in a patient with Lowe syndrome and a splice site mutation in the OCRL1 gene. Klin Monatsbl Augenheilkd 224:207-209.

Kubota T, Sakurai A, Arakawa K, Shimazu M, Wakui K, Furihata K, Fukushima Y. 1998. Identification of two novel mutations in the OCRL1 gene in Japanese families with Lowe syndrome. Clin Genet 54:199-202.

Leahey AM, Charnas L, Nussbaum R. 1993. Nonsense mutations in the OCRL-1 gene in patients with the oculocerebrorenal syndrome of Lowe. Hum Mol Genet 4:461-463.

Lichter-Konecki U, Farber LW, Cronin JS, Suchy SF, Nussbaum RL. 2006. The effect of missense mutations in the RhoGAP-homology domain on ocrl1 function. Mol Genet Metabol $89: 121-128$

Lin T, Orrison B, Leahey AM, Suchy S, Bernard D, Lewis R, Nussbaum R. 1997. Spectrum of mutations in the OCRL1 gene in the Lowe oculocerebrorenal syndrome. Am J Hum Genet 60:1384-1388.

Lin T, Orrison BM, Suchy SF, Lewis RA, Nussbaum RL. (1998). Mutations are not uniformly distributed throughout the OCRL1 gene in Lowe syndrome patients. Mol Genet Metabol 64:58-61.

Lloyd SE, Pearce SHS, Fischer SE, Steinmeyer K, Schwappach B, Scheinman SJ, Harding B, Bolino A, Devoto M, Goodyer P, Rigden SP, Wrong O, Jentsch TJ, Craig IW, Thakker RV. 1996. A common molecular basis for three inherited kidney stone diseases. Nature 379, 445449. 
Loi M. 2006. Lowe syndrome. Orphanet J Rare Dis 1:16-21.

Lowe C, Terrey M, MacLachan E. 1952. Organic aciduria, decreased renal ammonia production, hydrophtalmos, and mental retardation: a clinical entity. Am J Dis Child 83:164184.

Lowe M. 2005. Structure and function of the Lowe syndrome protein OCRL1. Traffic 6:711719.

Lowe Syndrome Mutation Database. 2010. http://resarch.nhgri.nih.gov/lowe/ Mazo Y, Balkin DM, Zoncu R, Erdmann KS, Tomasini L, Hu F, Jin MM, Hodsdon ME, De Camilli P. 2009. A PH domain within OCRL bridges clathrin-mediated membrane trafficking to phosphoinositide metabolism. EMBO J 28 :1831-42.

McCrea HJ, Paradise S, Tomasini L, Addis M, Melis MA, Dematteis MA, De Camilli P. 2008. All known patient mutations in the ASH-RhoGAP domains of OCRL affect targeting and APPL1 binding. Biochem Biophys Res Commun 369:493-499.

Monnier N, Satre V, Lerouge E, Berthoin F, Lunardi J. 2000. OCRL1 mutation analysis in French Lowe syndrome patients: implications for molecular diagnosis and genetic counselling. Hum Mutation 16:157-165.

Nussbaum R, Orrison M, Jänne P, Charnas L, Chinault A. 1997. Physical mapping and genomic structure of the Lowe syndrome gene OCRL1. Hum Genet 99, 145-150.

Olivos-Glander I, Jänne P, Nussbaum R. 1995. The oculocerebral syndrome gene product is a 105-kD protein localized to the Golgi complex. Am J Hum Genet 57:817-823.

Peck J, Douglas GT, Wu CH, Burbelo PD. 2002. Human RhoGAP domain-containing proteins: structure, function and evolutionary relationships. FEBS Lett 528:239-242. 
Peverall J, Edkins E, Goldblatt J, Murch A. 2000. Identification of a novel deletion of the entire OCRL1 gene detected by FISH analysis in a family with Lowe syndrome. Clin Genet 58:479-482.

Piwon N, Günther W, Schwake M. 2000. ClC-5 $\mathrm{Cl}^{-}$-channel disruption impairs endocytosis in a mouse model for Dent's disease. Nature 408:369-373.

Röschinger W, Muntau AC, Rudolph G, Roscher AA, Kammerer S. 2000. Carrier assessment in families with Lowe oculocerebrorenal syndrome: novel mutations in the OCRL1 gene and correlation of direct DNA diagnosis with ocular examination. Mol Genet Metabol 69: 213222.

Satre V, Monnier N, Berthoin F, Ayuso C, Joannard A, Jouk PS, Lopez-Pajares I, Megabarne A, Jean Philippe H, Plauchu H, Torres ML, Lunardi J. 1999. Characterization of a germline mosaicism in families with Lowe syndrome and identification of seven novel mutations in the OCRL1 gene. Am J Hum Genet 65:68-76.

Schneider JF, Boltshauser E, Neuhaus TJ, Rauscher C, Martin E. 2001. MRI and proton spectroscopy in Lowe syndrome. Neuropediatrics 32:45-48.

Schröder M, Kaufman RJ. 2005. The mammalian unfolded protein response. Ann Rev Biochem 74:739-89.

Sekine T, Nozu K, Iyengar R, Jun Fu X, Matsuo M, Tanaka R, Iijima K, Matsui E, Harita Y, Inatomi J, Igarashi, T. 2007. OCRL1 mutations in patients with Dent disease phenotype in Japan. Pediatr Nephrol 22:975-980.

Sehti SK, Bagga A, Gulati A, Hari P, Gupta N, Lunardi J. 2008. Mutations in OCRL1 gene in Indian children with Lowe syndrome. Clin Exp Nephrol 12:358-362.

Shrimpton AE., Hoopes RR Jr, Knohl SJ, Hueber P, Reed AA, Christie PT, Igarashi T, Lee P, Lehman A, White C, Milford DV, Sanchez MR, Unwin R, Wrong OM, Thakker RV, 
Scheinman SJ.2009. OCRL1 mutations in Dent 2 patients suggest a mechanism for phenotypic variability. Nephron Physiol 112:27-36.

Suchy S, Olivos-Glander I, Nussbaum R. 1995. Lowe syndrome, a deficiency of a phosphatidylinositol 4,5-bis-inositol-4,5-biphosphate 5-phosphatase. Hum Mol Biol 4:22452250 .

Suchy SF, Nussbaum RL. 2002. The deficiency of PiP2-5-phosphatase in Lowe syndrome affects actin polymerization. Am J Hum Genet 71:1420-1427.

Swan LE, Romasini L, Pirrucello M, Lunardi J, De Camilli P. 2010. Two closely related endocytic proteins that share a common OCRL-binding motif with APPL1. Proc Natl Acad Sci USA 107:3511-3516.

Ungewickell AJ, Waed ME, Ungewickell E, Majerus PW. 2004. The inositol polyphosphate 5-phosphatase Ocrl associates with endosomes that are partially coated with clathrin. Proc Natl Acad Sci USA 101:13501-13506.

Thakker RV. 2000. Pathogenesis of Dent's disease and related syndromes of X-linked nephrolithiasis. Kidney Int 57: 787-93.

Tosetto E, Addis M, Caridi G, Meloni C, Emma F, Vergine F, Stringini G, Papalia T, Barbano G, Ghiggeri GM, Ruggeri L, Miglietti N, D’Angelo A, Melis MA, Anglani F. 2009. Locus heterogeneity of Dent's disease: OCRL1 and TMEM27 genes in patients with no CLCN5 mutations. Pediatr Nephrol 24:1967-1973.

Tsujishita Y, Guo S, Stolz LE, York JD, Hurley JH. 2001. Specificity determinants in phosphoinositide dephosphorylation: crystal structure of an archetypal inositol polyphosphate 5-phosphatase. Cell 105:379-389.

Utsch B, Bökenkamp A, Benz MR, Besbas N, Dötsch J, Franke I, Fründ S, Kok F, Hoppe B, Karle S, Kuwerz-Bröking E, Lazube G, Neb M, Nuutinen M, Ozaltin F, Rascher W, Ring T, 
Tasic V, van Wijk JA, Ludwig M. 2006. Novel OCRL1 mutations in patients with the phenotype of Dent disease. Am J Kidney Dis 48:942-954.

Whisstock JC, Romerao S, Gurung R, Nandurkar H, Ooms LM, Bottomley SP, Mitchell CA. 2001. The inositol polyphosphate 5-phosphatases and the apurinic/apyrimidic base excision repair endonucleases share a common mechanism for catalysis. J Biol Chem 275:3705537061.

Zhang X, Jefferson AB, Avethavekiat V, Majerus PW. 1995. The protein deficient in Lowe syndrome is a phosphatidylinositol-4,5-biphosphate 5-phosphatase. Proc Natl Acad Sci USA 92:4853-4856. 


\section{LEGENDS OF FIGURES}

Figure 1. Mapping of mutations associated with Lowe syndrome and Dent's disease in the OCRL1 gene.

Exons, including the alternatively spliced exon $18 \mathrm{a}$, are numbered 1 to 23 and are drawn to scale at the exception of the non-coding sequence of exon 23. The catalytic phosphatase domain is indicated in black, the PH domain in hatched, the ASH-Rab binding domain in light grey, the Rho-GAP like domain as a punctuated pattern and the 5' and 3' untranslated regions are shown in dark grey. LIDIA and LIDLE refer to motives involved in clathrin binding [Mao et al., 2009] and FEDNF to amino-acids involved in AP-2 clathrin adaptator binding [Ungewickell et al., 2004]. Frameshift and nonsense mutations are indicated using their cDNA numbering above the schematic representation of the cDNA while missense mutations and in frame deletions are presented below the cDNA and designated by their protein numbering. Mutations indicated in bold correspond to nonsense mutations. Stars refer to intronic mutations leading to splicing defects. Horizontal bars indicated gross genomic deletions.

Figure 2. Quantification of mRNA OCRL1 expression in patients harbouring a mutation of the $O C R L 1$ gene.

OCRL1 and GAPDH mRNAs were isolated from fibroblasts and quantified as described in Material and Methods. Horizontal black bar represent the mean and upper and lower boxes the 2 SD limits. Arrow points to the ratio value measured in a patient affected by Dent Disease and harbouring a c.40-14G>A mutation.

Figure 3. mRNA and protein expression of the c.40-14 A $>$ G mutation. 
Panel A. cDNA obtained from fibroblasts harbouring the c.40-14A $>$ G mutation was amplified using primers allowing amplification of a sequence encompassing exons 1, 2 and 3.

Amplification products were analyzed using a 2\% agarose gel. Amplification of the mutant cDNA (lane 1) generated two bands respectively long of 288 and 391 bp (arrows) while amplification of the normal sequence (lane 2) generated a $488 \mathrm{bp}$ fragment as expected. Panel B. Western blotting of fibroblast extracts was performed as described in Material and Methods. Lanes 1, 4: control fibroblasts; lane 2: c.40-14A>G mutant fibroblasts; lane 3: p.Ile274Thr mutant fibroblasts.

Figure 4. Western blot analysis of OCRL1 in control and patient fibroblasts.

Fibroblasts extract $(25 \mu \mathrm{g})$ prepared as described in Material and Methods was loaded in each lane. Upper panel: western blot analysis using polyclonal antibodies directed againts OCRL1. Lane M: molecular weight markers, lanes 1, 7, 8, 12 : control patients, lane 2: p.Glu468Gly, lane 3: p.Arg318Cys, lane 4: p.Asn373Tyr, lane 5: p.Pro801Cys, lane 6: p.Pro799Leu, lane 9: p. Arg810Stop, lane 10: c. $2469+2 T>G$, lane 11: c.825-2A>G. Lower panel: protein loading in the different lanes was demonstrated by a western blot analysis of the same blot with the use of antibody against the $\beta$ subunit of the mitochondrial ATPase .

Figure S1. Conservation of residues located in the phosphatidyl-inositol phosphatase catalytic domain and in the Rab and Rho-GAP domains of OCRL1 and related proteins. Amino acids alignment is given with identical residues shown by dashes. Mutated residues are shown in bold. Numbering of the amino-acids refer to the human OCRL1 sequence (ENSP00000360154). Upper amino acids represent the missense mutations identified in patients affected by Lowe syndrome and Dent disease (underlined character). Sequences were obtained from SwissProt and Genbank with the following accession number. OCRL1: H. 
sapiens Q01968, M. musculus Q6NVF0, C. elegans NM 060183, D. melanogaster NP

569962; INPP5B: NP005531; INPPL1: NP001558; SHIP: NP001017915; Synaptojanin:

NP003886; ARHGAP10: AAI09030; RHOGAP4: NP001657; Oligophrenin: O60890; RACGAP1: AAH32754 .

Figure S2. Schematic representation of the splicing consequences of the c.40-14G>A mutation.

Element involved in the splicing (donor and acceptor sites) of normal and mutant exons 1, 2 and 3 are indicated in the sequences (bold character). The c.40-14A $>$ G mutation (underlined character) revealed a cryptic donor site in exon 1 located in position -82 that was used for both mutated transcripts. In mutant transcript \#1 splicing used a cryptic acceptor site of intron 1 at position -24 while exon 2 was completely skipped in mutant transcript \#3. This representation was based on sequencing data obtained after cloning of the different transcripts that have been evidenced. 


1
2
3
4
5
6
7
8
9
10
11
12
13
14
15
16
17
18
19
20
21
22
23
24
25
26
27
28
29
30
31
32
33
34
35
36
37
38
39
40
41
42
43
44
45
46
47
50
58
59
50
52
53
50

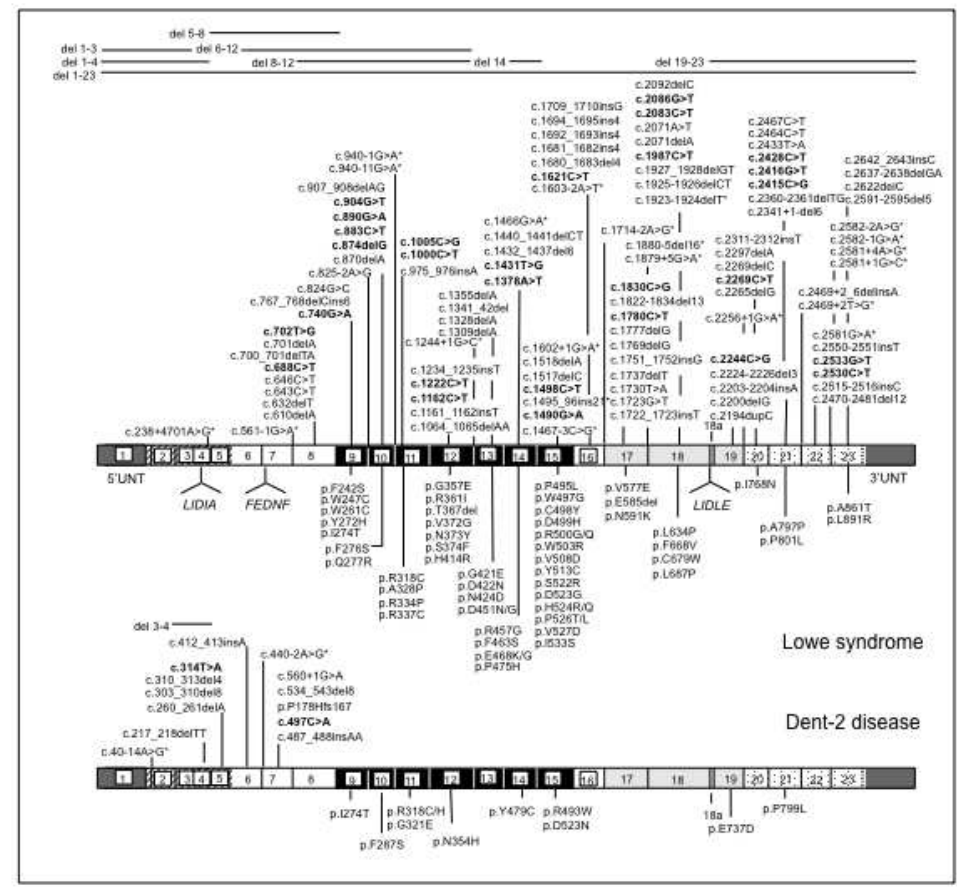

$275 \times 190 \mathrm{~mm}(72 \times 72$ DPI $)$

John Wiley \& Sons, Inc. 


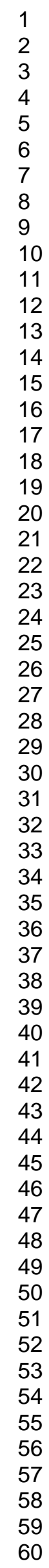

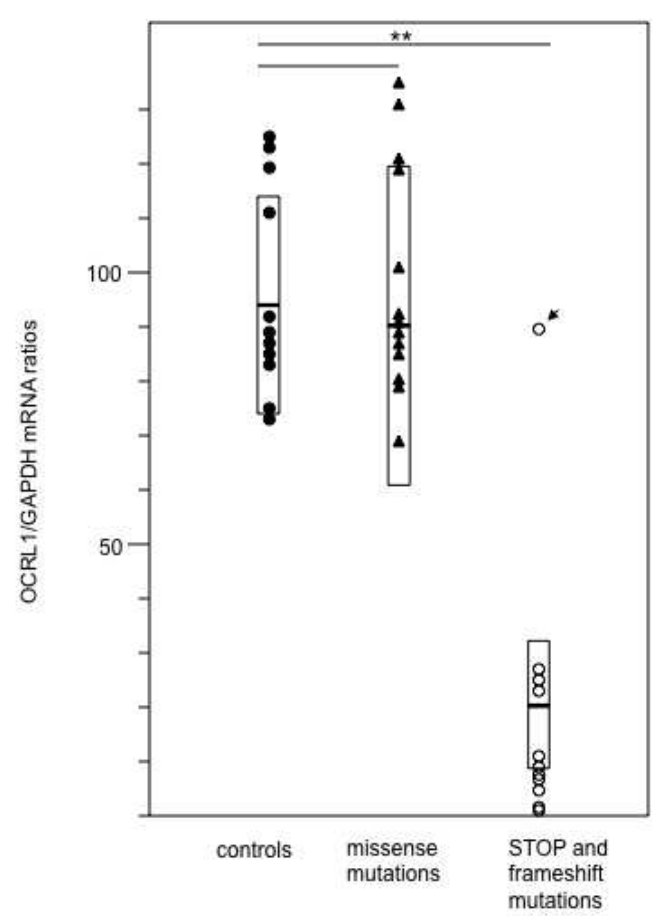

Figure 2 $254 \times 190 \mathrm{~mm}(72 \times 72$ DPI $)$

John Wiley \& Sons, Inc. 


1
2
3
4
5
6
7
8
9
10
11
12
13
14
15
16
17
18
19
20
21
22
23
24
25
26
27
28
29
30
31
32
33
34
35
36
37
38
39
40
41
42
43
40
45
49
50
51
52
53
55
50
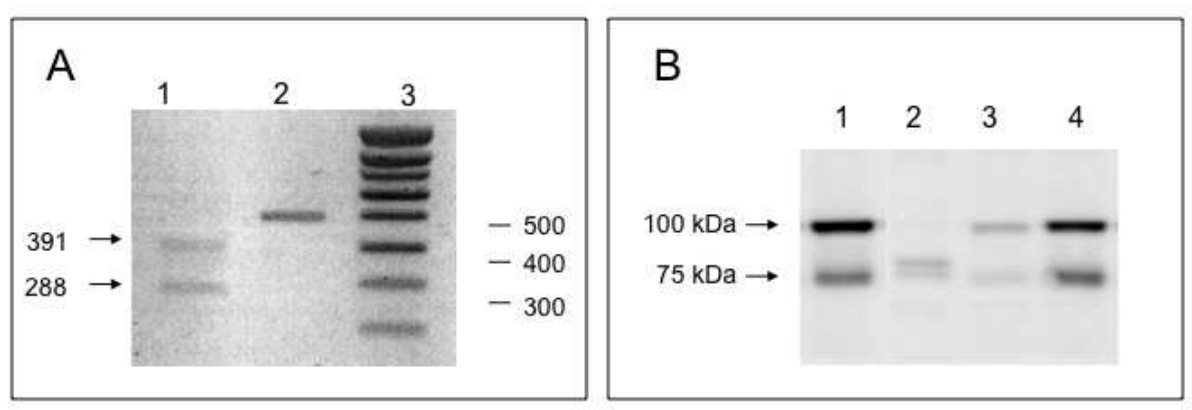

Figure 3

$254 \times 190 \mathrm{~mm}(72 \times 72$ DPI $)$

John Wiley \& Sons, Inc. 
Figure 4 $254 \times 190 \mathrm{~mm}(72 \times 72$ DPI $)$

John Wiley \& Sons, Inc. 


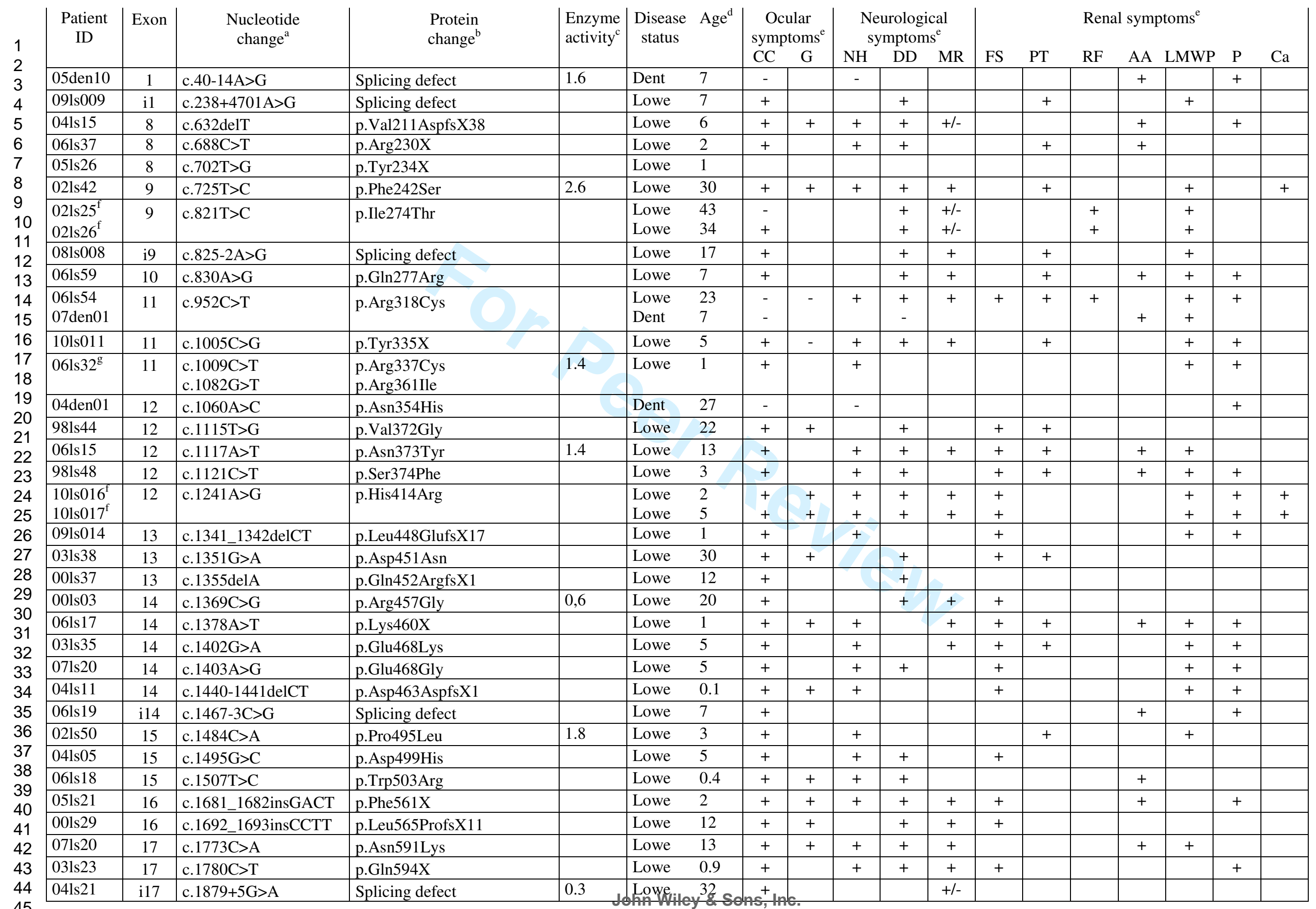




\begin{tabular}{|c|c|c|c|c|c|c|c|c|c|c|c|c|c|c|c|c|c|c|}
\hline $001 s 23$ & 18 & c.1927_1928delGT & p.Val643AsnfsX8 & 1.8 & Lowe & 0.3 & + & & + & + & & & + & & + & + & & \\
\hline $021 \mathrm{~s} 35$ & 18 & c. $2086 \mathrm{G}>\mathrm{T}$ & p.Glu696X & & Lowe & 20 & + & & & + & + & & + & & & + & & + \\
\hline $071 \mathrm{~s} 10$ & 18 & c.2092delC & p.Pro681LeufsX66 & & Lowe & dead & + & & + & & & & & & & & & \\
\hline $081 \mathrm{~s} 011$ & 19 & c.2194dupC & p.Leu732PfsX38 & & Lowe & 1 & + & + & + & + & + & + & + & & & + & & \\
\hline $021 s 11$ & 19 & c. $2200 \mathrm{delG}$ & p.Val734PhefsX8 & & Lowe & 6 & + & & + & & & + & & & & & & \\
\hline $081 \mathrm{~s} 15$ & 19 & c.2224_2226delGTA & p.Val742del & & Lowe & 10 & + & + & + & + & + & + & + & + & + & + & + & + \\
\hline $981 s 54$ & 20 & c. $2269 \mathrm{C}>\mathrm{T}$ & p.Gln757X & & Lowe & 23 & + & & + & + & + & $+/-$ & + & + & + & + & + & \\
\hline $\begin{array}{l}\text { 051s29 } \\
\text { 091s001 }\end{array}$ & 20 & c.2311-2312insT & p.Cys771LeufsX8 & & $\begin{array}{l}\text { Lowe } \\
\text { Lowe }\end{array}$ & $\begin{array}{l}7 \\
2\end{array}$ & $\begin{array}{l}+ \\
+\end{array}$ & & $\begin{array}{l}+ \\
+\end{array}$ & $\begin{array}{l}+ \\
+\end{array}$ & + & + & + & & & $\begin{array}{l}+ \\
+\end{array}$ & + & \\
\hline $041 \mathrm{~s} 17$ & 21 & c. $2464 \mathrm{C}>\mathrm{T}$ & p.Arg822X & & Lowe & 2 & + & + & + & + & & & + & & & + & & \\
\hline $051 \mathrm{ls} 17$ & $\mathrm{i} 21$ & c. $2469+2 \mathrm{~T}>\mathrm{G}$ & Splicing defect & 0.3 & Lowe & 1 & + & & + & + & $+/-$ & & + & + & & + & & \\
\hline $011 \mathrm{~s} 19$ & $\mathrm{i} 22$ & c. $2581+1 \mathrm{G}>\mathrm{C}$ & Splicing defect & & Lowe & 1.5 & + & + & & & & & & & & & & \\
\hline $031 \mathrm{ls} 14$ & $\mathrm{i} 22$ & c. $2582-1 \mathrm{G}>\mathrm{A}$ & Splicing defect & & Lowe & 23 & + & & & & + & & + & & & + & & \\
\hline $061 \mathrm{~s} 65$ & $\mathrm{i} 22$ & c. $2582-2 \mathrm{~A}>\mathrm{G}$ & Splicing defect & & Lowe & 6 & + & & + & + & + & + & + & & + & + & & \\
\hline $081 \mathrm{~s} 03$ & 23 & c. $2591 \_2595$ del6 & p.Gln879_Thr880>HisfsX4 & & Lowe & 28 & + & + & + & + & + & & + & & + & + & & \\
\hline $021 \mathrm{~s} 08$ & 23 & c.2637_2638del & p.Gln862HisfsX3 & & Lowe & 12 & + & & & & + & & & & & & & \\
\hline $091 \mathrm{~s} 013$ & 23 & c. $2672 \mathrm{~T}>\mathrm{G}$ & p.Leu891Arg & & Lowe & 10 & + & & + & + & & & + & & + & & & \\
\hline 06den06 & $3-4$ & del exon 3-4 & Frameshift deletion & & Dent & 9 & - & & - & - & - & & + & & & + & & + \\
\hline $001 \mathrm{~s} 05$ & $19-23$ & del exons 19-23 & Frameshift deletion & 1.8 & Lowe & 30 & + & & + & + & + & + & & & & & & \\
\hline
\end{tabular}

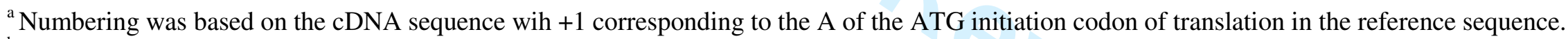

${ }^{\mathrm{b}}$ Expected consequences of the mutations with codon 1 corresponding to the ATG initiation codon of translation.

${ }^{c}$ Enzyme activity measured in controls was $\mathrm{N}=9.6+/-2.3$ nanomoles $\mathrm{PI}(4,5) \mathrm{P}_{2}$ hydrolyzed $/ \mathrm{min} / \mathrm{mg}$

${ }^{\mathrm{d}}$ Age at the time of the molecular investigation

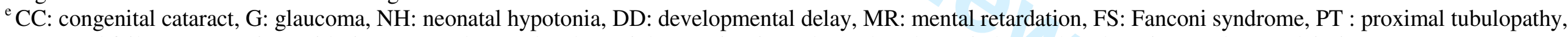

RF: renal failure, AA: amino-aciduria, LMWP: low molecular weight proteinuria; P: hypophosphatemia/hyperphosphaturia, Ca : hypercalciuria.

(+) sign present, (-) sign absent, ( ) sign not documented at the time of the last examination

${ }^{\mathrm{f}}$ Patients $021 \mathrm{~s} 25$ and $021 \mathrm{~s} 26$, and $101 \mathrm{~s} 06$ and $101 \mathrm{~s} 017$ are brothers

g Variants c. $1009 \mathrm{C}>\mathrm{T}$ and c. $1082 \mathrm{G}>\mathrm{T}$ are on the same allele

Table 1 : Novel mutations in the OCRL1 gene 
Patients with missense mutations ${ }^{\mathrm{b}}$

Patients with nonsense or frameshift mutations ${ }^{\mathrm{b}}$

Patients with no OCRL1 mutation identified ${ }^{\mathrm{c}}$

Control individuals enzyme activity ${ }^{\mathrm{a}}$

(nanomol PI $(4,5) \mathrm{P}_{2}$ hydrolyzed $\mathrm{mg}^{-1} \mathrm{~min}^{-1}$ ) $(+/-$ SEM)

$$
\begin{aligned}
& 1.39+/-0.99(\mathrm{n}=12) \\
& 1.54+/-0.63(\mathrm{n}=11) \\
& 9.43+/-1.47(\mathrm{n}=12) \\
& 9.62+/-2.31(\mathrm{n}=13)
\end{aligned}
$$

\footnotetext{
${ }^{a} \mathrm{n}$ value represent the number of independent patients tested, all measurements

${ }^{\mathrm{b}} 19$ patients were affected by Lowe syndrome, 4 presented with Dent- 2 disease ${ }^{\mathrm{c}}$ these patients were adressed to the laboratory for molecular and biochemical investigations. on the basis of suspicion of Lowe syndrome
}

\section{Table 2. PI(4,5) $P_{2}$ phosphatase activity in patients with OCRL1 mutations}


OCRL1 / $\beta$ ATPase ${ }^{a}$ relative units $(+/$-SEM)

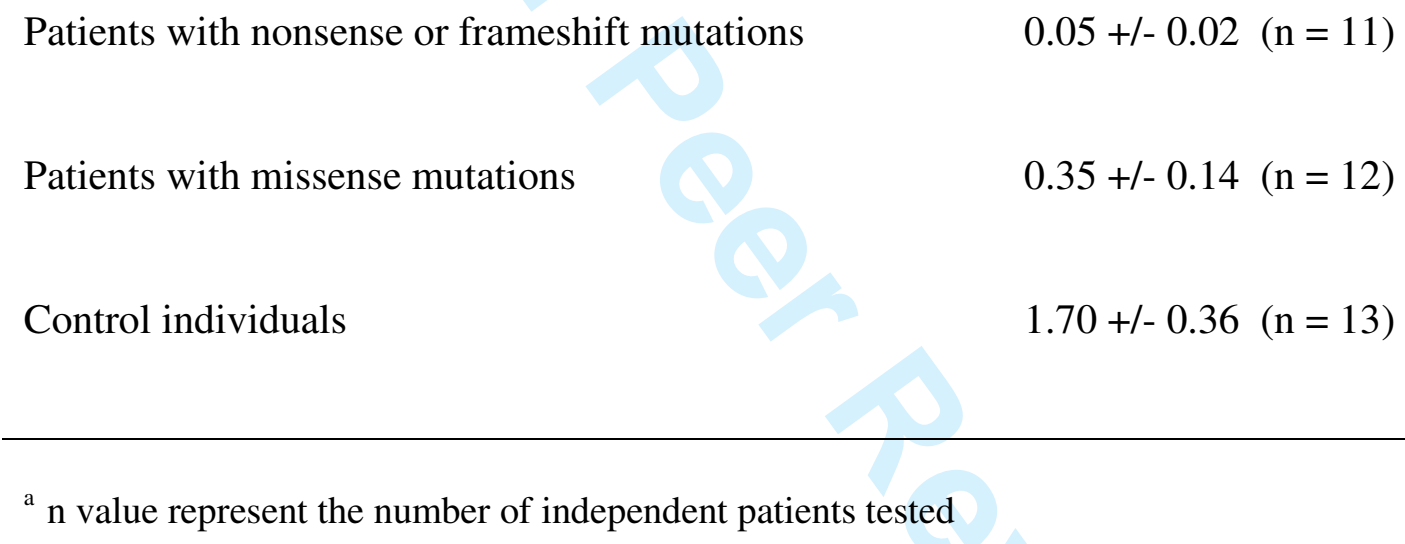

${ }^{\mathrm{a}} \mathrm{n}$ value represent the number of independent patients tested

Table 3. OCRL1 content in fibroblasts originating from patients with OCRL1 mutations 


\begin{tabular}{|c|c|c|c|c|c|c|c|}
\hline $\begin{array}{l}\text { Patient } \\
\text { ID }\end{array}$ & $\begin{array}{l}\text { Clinical } \\
\text { diagnosis }^{\mathrm{a}}\end{array}$ & Mutation & $\operatorname{Age}^{b}$ & $\begin{array}{l}\mathrm{PiP}_{2} \text { ase } \\
\text { activity }^{\mathrm{c}}\end{array}$ & $\begin{array}{l}\text { Ocular } \\
\text { symptoms }\end{array}$ & $\begin{array}{l}\text { SNC } \\
\text { symptomss }\end{array}$ & $\begin{array}{l}\text { Renal } \\
\text { symptoms }\end{array}$ \\
\hline $981 \mathrm{~s} 18$ & Lowe & del exons $1-4$ & 3 & & $\begin{array}{l}\text { Congenital } \\
\text { bilateral cataract }\end{array}$ & $\begin{array}{l}\text { Neonatal hypotonia, } \\
\text { convulsions }\end{array}$ & Fanconi syndrome \\
\hline $06 \mathrm{den} 06$ & Dent & del exon 3-4 & 14 & & None & None & LMW proteinuria, hypercalciuria \\
\hline $021 \mathrm{~s} 25^{\mathrm{d}}$ & Lowe & p.Ile274Thr & 43 & & None & $\begin{array}{l}\text { Moderate mental retardation } \\
\text { allowing an autonomous life }\end{array}$ & $\begin{array}{l}\text { Nephrotic syndrome, proteinuria, } \\
\text { renal failure }\end{array}$ \\
\hline $021 \mathrm{~s} 26^{\mathrm{d}}$ & Lowe & p.Ile274Thr & 34 & & $\begin{array}{l}\text { Congenital } \\
\text { unilateral cataract }\end{array}$ & $\begin{array}{l}\text { Moderate mental retardation } \\
\text { allowing an autonomous life }\end{array}$ & Renal failure, proteinuria \\
\hline $05 \operatorname{den} 11$ & Dent & p.Ile274Thr & 2 & 6 & None & Developmental delay & $\begin{array}{l}\text { Proximal tubulopathy, proteinuria, } \\
\text { hypercalciuria }\end{array}$ \\
\hline 061s59 & Lowe & p.Arg318Cys & 24 & & Severe myopia & $\begin{array}{l}\text { Neonatal hypotonia, severe } \\
\text { mental retardation }\end{array}$ & $\begin{array}{l}\text { Fanconi syndrome, proteinuria, } \\
\text { hyperphophaturia, renal failure }\end{array}$ \\
\hline 07den01 & Dent & p.Arg318Cys & 4 & & None & None & Tubular proteinuria, hypercalciuria \\
\hline $981 s 80$ & Lowe & p.Ala797Pro & 57 & 2.9 & $\begin{array}{l}\text { Congenital } \\
\text { bilateral cataract }\end{array}$ & $\begin{array}{l}\text { Moderate mental retardation } \\
\text { and mild psychomotor } \\
\text { troubles }\end{array}$ & Fanconi syndrome \\
\hline 04 den 05 & Dent & p.Pro799Leu & 21 & 0.8 & None & None & $\begin{array}{l}\text { LMW proteinuria, hypercalciuria, } \\
\text { nephrocalcinosis, } \\
\text { hyperphosphaturia, aminoaciduria }\end{array}$ \\
\hline $061 \mathrm{~s} 27$ & Lowe & p.Pro801Leu & 1 & 1.6 & $\begin{array}{l}\text { Congenital } \\
\text { bilateral cataract }\end{array}$ & $\begin{array}{l}\text { Neonatal hypotonia, } \\
\text { moderate developmental } \\
\text { delay, no psychomotor } \\
\text { troubles }\end{array}$ & Glomerular and tubular proteinuria \\
\hline
\end{tabular}

${ }^{a}$ initial clinical diagnosis

${ }^{b}$ age at the time of the molecular investigation

${ }^{c}$ enzyme activity measured in controls was $\mathrm{N}=9.6+/-2.3$ nanomoles $\mathrm{PI}(4,5) \mathrm{P}_{2}$ hydrolyzed $/ \mathrm{min} / \mathrm{mg}$

d patients $021 \mathrm{~s} 25$ and $021 \mathrm{~s} 26$ are brothers

Table 4. Clinical expression of OCRL1 mutations in patients affected by Lowe syndrome or Dent disease 
OCRL1 H. saplens. OCRL1 M. muscult

OCrLi C. Elegans

INPESB H. sapiens

INPPL1 $\mathrm{H}$. Saplen

Synaptojanin $\mathrm{H}$. sapten
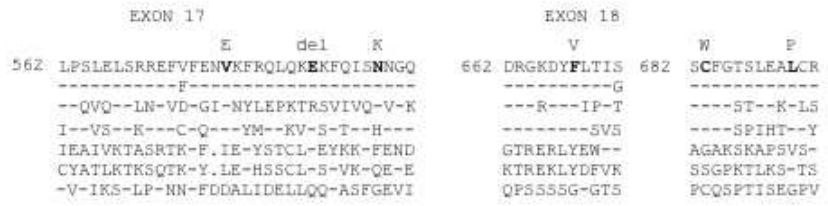

EXN 20

OCRLI H. saptens

OCKL1 M. musculus:

OCRL1 C. Elegans

AR̆GGAPIO H. sapten

RHOGAP4 H. Bap1ens

ollgoparentn H. saplens 765
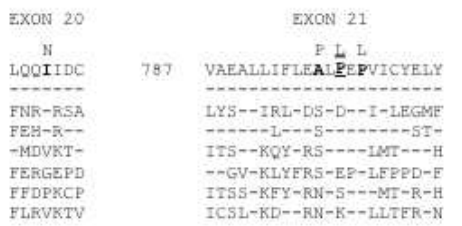

Supplementary Figure 1 $254 \times 190 \mathrm{~mm}(72 \times 72$ DPI $)$

John Wiley \& Sons, Inc. 
w1ld-type transcript

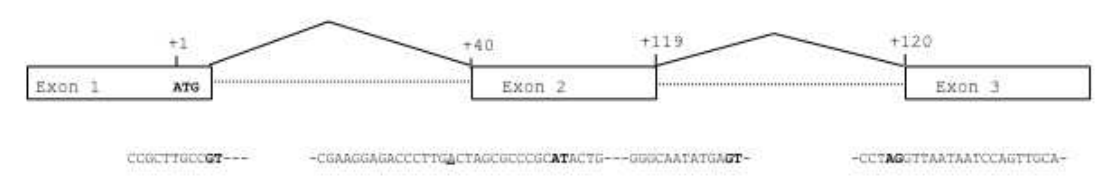

mutant transcript $\# 1$
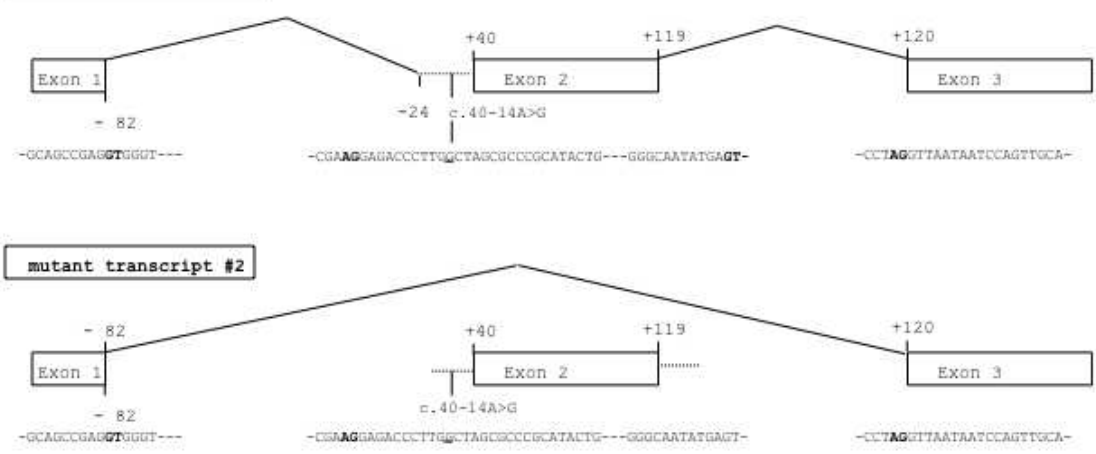

Supplementary Figure 2 $254 \times 190 \mathrm{~mm}$ ( $72 \times 72$ DPI)

John Wiley \& Sons, Inc. 


\begin{tabular}{|c|c|c|}
\hline \multirow{2}{*}{ exon } & \multirow{2}{*}{ Previous numbering ${ }^{\mathrm{a}}$} & \multirow[b]{2}{*}{ Corrected numbering } \\
\hline & & \\
\hline 1 & to -13 & -169 to 39 \\
\hline 2 & -12 to 68 & 40 to 119 \\
\hline 3 & 69 to 148 & 120 to 199 \\
\hline 4 & 149 to 187 & 200 to 238 \\
\hline 5 & 188 to 298 & 239 to 349 \\
\hline 6 & 299 to 388 & 350 to 439 \\
\hline 7 & 389 to 509 & 440 to 560 \\
\hline 8 & 510 to 670 & 561 to 722 \\
\hline 9 & 671 to 773 & 723 to 824 \\
\hline 10 & 774 to 888 & 825 to 939 \\
\hline 11 & 889 to 1004 & 940 to $\mathbf{1 0 5 6}$ \\
\hline 12 & 1005 to 1193 & $\mathbf{1 0 5 7}$ to 1244 \\
\hline 13 & 1194 to 1304 & 1245 to $\mathbf{1 3 5 6}$ \\
\hline 14 & 1305 to 1415 & $\mathbf{1 3 5 7}$ to 1466 \\
\hline 15 & 1416 to 1551 & 1467 to 1602 \\
\hline 16 & 1552 to 1662 & 1603 to 1713 \\
\hline 17 & 1663 to 1828 & 1714 to 1879 \\
\hline 18 & 1829 to 2064 & 1880 to 2115 \\
\hline $18 \mathbf{a}$ & 2065 to 2088 & 2116 to 2140 \\
\hline 19 & 2089 to 2205 & 2141 to 2256 \\
\hline 20 & 2206 to 2290 & 2257 to 2341 \\
\hline 21 & 2291 to 2418 & 2342 to 2469 \\
\hline 22 & 2419 to 2530 & 2470 to 2581 \\
\hline 23 & 2531 to 4935 & 2582 to 4986 \\
\hline
\end{tabular}

\footnotetext{
${ }^{\text {a }}$ Previous numbering [Attree et al.,1992; LSMD, 2010]

${ }^{\mathrm{b}}$ Conversion of previous numbering using the ATG start codon of exon 1 ( $\left.+51 \mathrm{bp}\right)$, bold numbers correspond to exons for which boundaries have been corrected
}

\section{Supplementary table 1. Numbering of exon boundaries}


Human Mutation

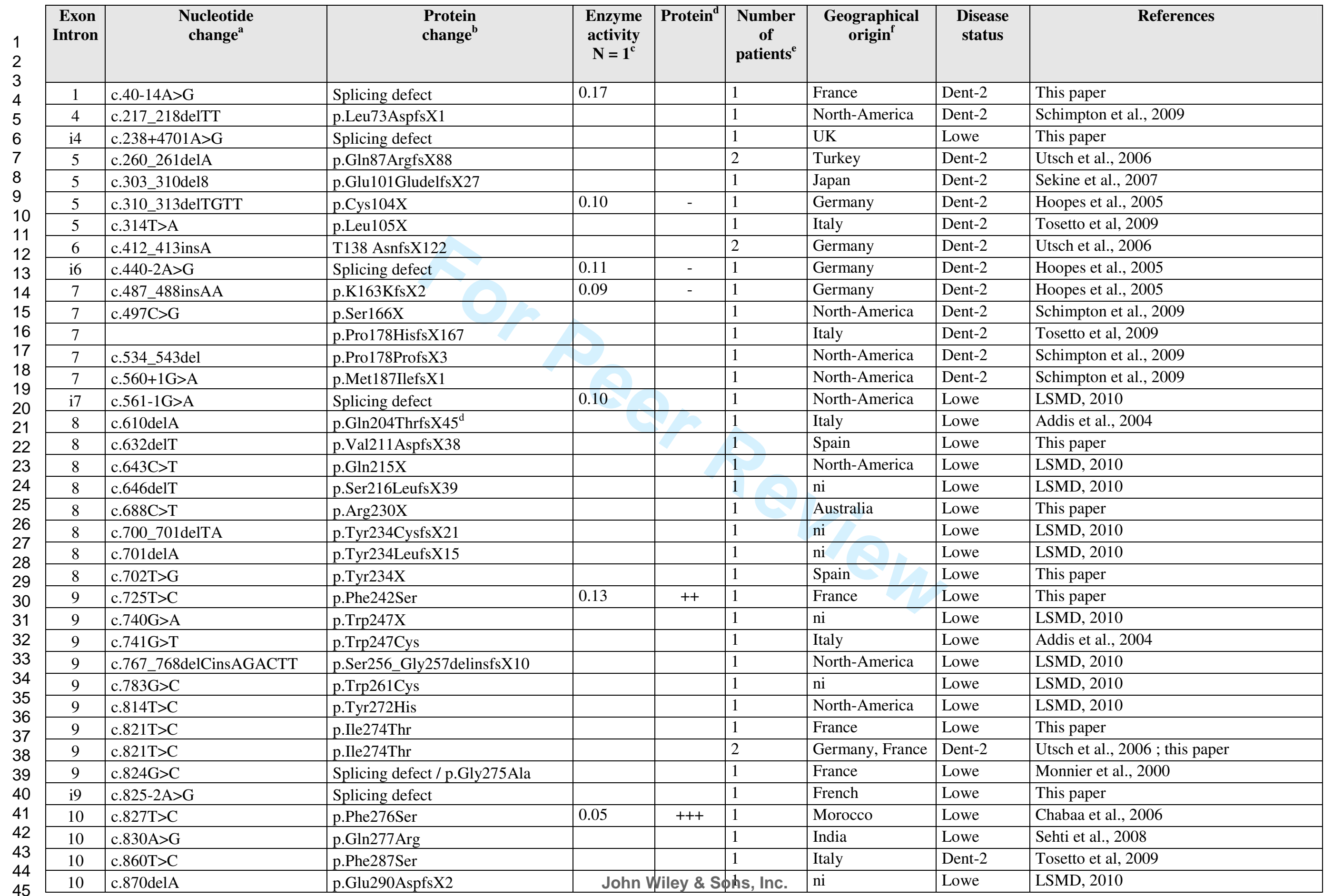




\begin{tabular}{|c|c|c|c|c|c|c|}
\hline p.Val292X & 0,05 & - & 1 & North-America & Lowe & Lin et al., 1997 \\
\hline p.Gln295X & & & 1 & North-America & Lowe & Lin et al., 1997 \\
\hline p.Trp297X & & & 1 & Germany & Lowe & LSMD, 2010 \\
\hline p.Glu302X & & & 1 & India & Lowe & Sehti et al., 2008 \\
\hline p.Arg303ArgfsX9 & & & 1 & France & Lowe & Monnier et al., 2000 \\
\hline Splicing defect & $0,13-0.17$ & - & 5 & \begin{tabular}{|l|} 
China, France \\
Norway, Japan \\
\end{tabular} & Lowe & Chou et al., 2005 ; this paper \\
\hline Splicing defect & & & 1 & ni & Lowe & Lin et al., 1998 \\
\hline p.Arg318Cys & $0.16-0.18$ & +++ & 3 & $\begin{array}{l}\text { Germany, France } \\
\text { Japan }\end{array}$ & Dent-2 & $\begin{array}{l}\text { Hoopes et al., } 2005 \text {; Sekine et al., } 2007 \text {; } \\
\text { this paper }\end{array}$ \\
\hline p.Arg318Cys & & & 1 & France & Lowe & This paper \\
\hline p.Arg318His & & & 1 & North-America & Dent-2 & Schimpton et al., 2009 \\
\hline p.Gly321Glu & & & 1 & North-America & Dent-2 & Schimpton et al., 2009 \\
\hline p.Leu325LeufsX14 & & & 1 & France & Lowe & Satre et al., 1999 \\
\hline p.Ala328Pro & & & 1 & ni & Lowe & Lin et al., 1998 \\
\hline p.Arg334X & 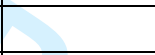 & & 3 & Spain, France & Lowe & Satre et al., 1999 ; Monnier et al., 2000 \\
\hline p.Arg334Pro & 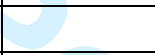 & & 1 & ni & Lowe & LSMD, 2010 \\
\hline p.Tyr335X & & & 1 & France & Lowe & This paper \\
\hline p.Arg337Cys & 0.15 & & 1 & France & Lowe & This paper \\
\hline p.Asn354His & & 8 & 1 & France & Dent-2 & This paper \\
\hline p.Lys355ArgdelfsX29 & & 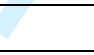 & 1 & ni & Lowe & LSMD, 2010 \\
\hline p.Gly357Glu & & & 2 & France & Lowe & Monnier et al., 2000 \\
\hline p.Arg361Ile & & & 1 & France & Lowe & This paper \\
\hline p.Thr367del & 0.01 & + & 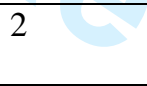 & $\begin{array}{l}\text { North-America } \\
\text { Spain }\end{array}$ & Lowe & Lin et al., 1997 ; Satre et al., 1999 \\
\hline p.Val372Gly & & & 1 & France & Lowe & This paper \\
\hline p.Asn373Tyr & 0.15 & ++ & 1 & France & Lowe & This paper \\
\hline p.Ser374Phe & & & 1 & France & Lowe & This paper \\
\hline p.His375Tyr & 0.0 & + & 1 & North-America & Lowe & Kubota et al., 1998 \\
\hline p.GIn388SerfsX4 & & & 1 & ni & Lowe & LSMD, 2010 \\
\hline p.Gln388X & 0.12 & - & 3 & \begin{tabular}{|l|} 
North-America \\
Japan, Germany
\end{tabular} & Lowe & $\begin{array}{l}\text { Lin et al., } 1997 \text {; Kubota et al., } 1998 \text {; } \\
\text { Röschinger et al., } 2000\end{array}$ \\
\hline p.Gln408X & & & 2 & Japan & Lowe & Kubota et al., 1998 \\
\hline p.Met412IlefsX4 & & & 1 & India & Lowe & Sehti et al., 2008 \\
\hline p.His414Arg & & & 2 & Kosovo & Lowe & This paper \\
\hline Splicing defect & & & 1 & Italy & Lowe & Addis et al., 2004 \\
\hline p.Gly421Glu & $0.05-0.19$ & + & 4 & \begin{tabular}{|l} 
Canada, \\
Switzerland \\
\end{tabular} & Lowe & Monnier et al., 2000 ; this paper \\
\hline p.Asp422Asn & & & 1 & ni & Lowe & LSMD, 2010 \\
\hline p.Asn424Asp & & & 1 & France & Lowe & Monnier et al., 2000 \\
\hline p.Ser437ValfsX12 & & & 1 & & Lowe & LSMD, 2010 \\
\hline
\end{tabular}


\begin{tabular}{l|l}
13 & c.1341_1342delCT \\
\hline 13 & c.1328delA
\end{tabular} $13 \quad$ c. $1352 \mathrm{~A}>\mathrm{G}$

13 c.1355delA

\begin{tabular}{ll|l}
14 & c. $1369 \mathrm{C}>\mathrm{G}$ \\
\hline 14 & $\mathrm{c} .1378 \mathrm{~A}>\mathrm{T}$ \\
\hline
\end{tabular}

\begin{tabular}{ll|l}
14 & c. $1378 \mathrm{~A}>\mathrm{T}$ \\
\hline 14 & $\mathrm{c}$
\end{tabular}

\begin{tabular}{|l|l|}
\hline 14 & c. $1387 \mathrm{~T}>\mathrm{C}$ \\
\hline 14 & $\mathrm{c} .1402 \mathrm{G}>\mathrm{A}$ \\
\hline
\end{tabular}

\begin{tabular}{ll}
14 & c. $1402 \mathrm{G}>\mathrm{A}$ \\
\hline 14 & $\mathrm{c} .1403 \mathrm{~A}>\mathrm{G}$
\end{tabular}

\begin{tabular}{l|l|l}
14 & $\mathrm{c} .1403 \mathrm{~A}>\mathrm{G}$ \\
\hline
\end{tabular}

$14 \quad$ c. $1424 \mathrm{G}>\mathrm{A}$

\begin{tabular}{l|l|l}
14 & c. $1431 \mathrm{~T}>\mathrm{G}$
\end{tabular}

14 c.1432_1437del6

\begin{tabular}{lll}
14 & c. $1436 \mathrm{~A}>\mathrm{G}$ \\
\hline 14 & $\mathrm{c} .1440-144$
\end{tabular}

14 c.1440-1441delCT

14 c.1466G $>$ A

\begin{tabular}{l|l}
\hline i14 & c.1467-3C $>\mathrm{G}$ \\
\hline 15 & c.1477C $>\mathrm{T}$
\end{tabular}

\begin{tabular}{ll}
15 & c. $1477 \mathrm{C}>\mathrm{T}$ \\
\hline 15 & $\mathrm{c} .1484 \mathrm{C}>\mathrm{A}$ \\
\hline
\end{tabular}

\begin{tabular}{l|l}
15 & c. $1484 \mathrm{C}>\mathrm{A}$ \\
\hline 15 & $\mathrm{c} 1489 \mathrm{~T}>\mathrm{G}$
\end{tabular}

\begin{tabular}{l|l}
15 & c. $1489 \mathrm{~T}>\mathrm{G}$ \\
\hline 15 & $\mathrm{c} .140 \mathrm{G}>\mathrm{A}$ \\
\hline
\end{tabular}

\begin{tabular}{ll}
15 & c. $1490 \mathrm{G}>\mathrm{A}$ \\
\hline & $\mathrm{c} .1493 \mathrm{G}>\mathrm{A}$
\end{tabular}

\begin{tabular}{ll|l}
15 & c. $1493 \mathrm{G}>\mathrm{A}$
\end{tabular}

$\begin{array}{ll}15 & \text { c. 1495-1496ins } 21\end{array}$

\begin{tabular}{l|l}
15 & c. $1498 \mathrm{C}>\mathrm{G}$ \\
\hline 15 & $\mathrm{c} .1498 \mathrm{C}>\mathrm{T}$
\end{tabular}

\begin{tabular}{ll|l}
\hline 15 & c. $1498 \mathrm{C}>\mathrm{T}$
\end{tabular}

\begin{tabular}{l|l}
15 & c. $1499 \mathrm{G}>\mathrm{A}$
\end{tabular}

$\begin{array}{ll}15 & \text { c. } 1507 \mathrm{~T}>\mathrm{C}\end{array}$

15 c.1518delA

\begin{tabular}{l|l}
15 & $\mathrm{c} .1523 \mathrm{~T}>\mathrm{A}$ \\
\hline 15 & $\mathrm{c} .1538 \mathrm{~A}>\mathrm{G}$ \\
\hline
\end{tabular}

\begin{tabular}{ll}
15 & c. $1538 \mathrm{~A}>\mathrm{G}$ \\
\hline 15 & $\mathrm{c} .1566 \mathrm{C}>\mathrm{G}$
\end{tabular}

\begin{tabular}{|l|l|}
\hline 15 & $\mathrm{c} .1566 \mathrm{C}>\mathrm{G}$ \\
\hline 15 & $\mathrm{c} 1567 \mathrm{G}>\mathrm{A}$ \\
\hline
\end{tabular}

\begin{tabular}{l|l|l|}
\hline 15 & $\mathrm{c} .1567 \mathrm{G}>\mathrm{A}$ \\
\hline 15 & $\mathrm{c} .1568 \mathrm{~A}>\mathrm{G}$ \\
\hline
\end{tabular}

\begin{tabular}{c|c}
15 & $\mathrm{c} .1568 \mathrm{~A}>\mathrm{G}$ \\
\hline 15 & $\mathrm{c} .157 \mathrm{~A}>\mathrm{G}$ \\
\hline
\end{tabular}

\begin{tabular}{ll}
15 & c. $1571 \mathrm{~A}>\mathrm{G}$ \\
\hline 15 & $\mathrm{c} .1572 \mathrm{C}>\mathrm{G}$ \\
\hline
\end{tabular}

\begin{tabular}{ll|l}
15 & c. $1576 \mathrm{C}>\mathrm{A}$
\end{tabular}

\section{Page 43 of 46} \begin{tabular}{l|l|}
\hline 13 & c.1328delA \\
\hline 13 & c.1351G $>\mathrm{A}$ \\
\hline 13 & $\mathrm{c} .1352 \mathrm{~A}>\mathrm{G}$ \\
\hline
\end{tabular}

\begin{tabular}{ll}
15 & c. $1495 \mathrm{G}>\mathrm{C}$ \\
\hline
\end{tabular}

\begin{tabular}{|l|l|}
\hline 15 & c. $1517 \mathrm{delC}$ \\
\hline 15 & $\mathrm{c} .1518 \mathrm{del}$ \\
\hline
\end{tabular}

\begin{tabular}{l|l}
15 & c. $1572 \mathrm{C}>\mathrm{G}$ \\
\hline 15 & $\mathrm{c} .1576 \mathrm{C}>\mathrm{A}$ \\
\hline
\end{tabular}
pLeu448GlufsX17 p.Asp443AlafsX6 p.Asp451Asn

p.Asp451Gly

p.Gln452ArgfsX2

p.Arg457Gly

p.Lys460X

p.Phe463Ser

p.Glu468Lys

p.Glu468Gly

p.Pro475His

P.Tyr477X

p.Lys479_Tyr480del

p.Tyr479Cys

p.Asp480AspfsX1

Splicing defect / p.Ser489Asn

Splicing mutation

p.Arg 493Trp

p.Pro495Leu

p.Trp497Gly

p.Trp497X

p.Cys498Tyr

p.Asp499His

p.Asp499delinsGRVPATCY

p.Arg500Gly

p.Arg500X

\section{p.Arg500Gln}

p.Trp503Arg

p.Thr506LysfsX13

pThr506ThrfsX13

p.Val508Asp

p.Tyr513Cys

p.Ser522Arg

p.Asp523Asn

p.Asp523Gly

p.His524Arg

p.His524Gln

p.Pro526Thr
Human Mutation
This paper

Monnier et al., 2000

This paper

Lin et al., 1997

This paper

This paper

This paper

Lin et al., 1997

This paper

This paper

Chou et al., 2005

Addis et al., 2004

Röschinger et al., 2000

Hoopes et al., 2005

This paper

Monnier et al., 2000

This paper

Utsch et al., 2006 ; Sekine et al., 2007

This paper

Schneider et al., 2001

LSMD, 2010

Monnier et al., 2000

This paper

Böckenhauer et al., 2008

Satre et al., 1999

Monnier et al., 2000 ; this paper

Serbia, France,

India

North-America Lowe

Japan, Germany,

France

France

Basque country

North-America

North-America Lowe

North-America Lowe

Italy

ni

Lowe

Dent-2

Lin et al., 1997 ; Kawano et al., 1998 ;

Röschinger et al., 2000 ; LSMD, 2010 ;

this paper

This paper

Monnier et al., 2000

Lin et al., 1997

Lin et al., 1998

Lin et al., 1998

Kubota et al., 1998

Tosetto et al, 2009

LSMD, 2010

Lin et al., 1997

Kawano et al., 1998

LSMD, 2010 


\begin{tabular}{|c|c|c|c|c|c|c|c|c|}
\hline 15 & c. $1577 \mathrm{C}>\mathrm{T}$ & p.Pro526Leu & & & 1 & Germany & Lowe & Röschinger et al., 2000 \\
\hline 15 & c. $1580 \mathrm{~T}>\mathrm{A}$ & p.Val527Asp & & & 1 & Italy & Lowe & Addis et al., 2004 \\
\hline 15 & c. $1598 \mathrm{~T}>\mathrm{G}$ & p.Ile533Ser & deficient & & 1 & ni & Lowe & LSMD, 2010 \\
\hline $\mathrm{i} 15$ & c. $1602+1 \mathrm{G}>\mathrm{A}$ & Splicing defect & 0.17 & + & 2 & Israel, France & Lowe & Monnier et al., 2000 ; this paper \\
\hline $\mathrm{i} 15$ & c. $1603-2 A>G$ & Splicing defect & & & 1 & ni & Lowe & Böckenhauer et al., 2008 \\
\hline 16 & c. $1621 \mathrm{C}>\mathrm{T}$ & p.Arg541X & & & 5 & France, India, ni & Lowe & LSMD, 2010 ; this paper \\
\hline 16 & c.1680_1683delCTTC & p.Asp560AspfsX4 & & & 1 & France & Lowe & Satre et al., 1999 \\
\hline 16 & c.1681_1682insGACT & p.Phe561X & & & 1 & Spain & Lowe & This paper \\
\hline 16 & c.16494_1695insCCTT & p.Leu565PhefsX11 & & & 4 & ni & Lowe & Addis et al., 2004 \\
\hline 16 & c.1709_1710insG & p.Arg570ArgfsX6 & & & 1 & France & Lowe & Monnier et al., 2000 \\
\hline i16 & $1714-2 \mathrm{~A}>\mathrm{G}$ & Splicing defect & & & 2 & Belgium, ni & Lowe & LSMD, 2010 ; this paper \\
\hline 17 & c. $1722-1723$ ins T & p.Glu575X & & & 1 & Germany & Lowe & Röschinger et al., 2000 \\
\hline 17 & c. $1723 \mathrm{G}>\mathrm{T}$ & p.Glu575X & & & 1 & Lebanon & Lowe & Satre et al., 1999 \\
\hline 17 & c. $1730 \mathrm{~T}>\mathrm{A}$ & Splicing defect / p.Val577Glu & & & 1 & Italy & Lowe & Addis et al., 2004 \\
\hline 17 & c.1737delT & p.Phe579PhefsX64 & 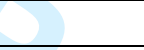 & & 1 & ni & Lowe & LSMD, 2010 \\
\hline 17 & c.1753_1755delGAG & p.Glu585del & 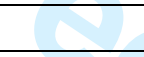 & & 1 & France & Lowe & Monnier et al., 2000 \\
\hline 17 & c.1769delG & P.Ser590ThrfsX53 & & $\Delta$ & 1 & ni & Lowe & LSMD, 2010 \\
\hline 17 & c. $1773 \mathrm{C}>\mathrm{A}$ & p.Asn591Lys & & & 1 & \begin{tabular}{|l|} 
Turkey \\
\end{tabular} & Lowe & This paper \\
\hline 17 & c. $1777 \mathrm{delG}$ & p.Gly593AspfsX51 & & & 1 & Spain & Lowe & Satre et al., 1999 \\
\hline 17 & c. $1780 \mathrm{C}>\mathrm{T}$ & p.Gln594X & & se & 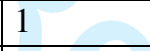 & Arabia & Lowe & This paper \\
\hline 17 & 1822_1834del13nt & p.Ser608_Lys312>SerfsX32 & & & 1 & France & Lowe & Monnier et al., 2000 \\
\hline 17 & $1830 \mathrm{C}>\mathrm{G}$ & p.Tyr613X & & & 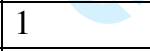 & ni & Lowe & LSMD, 2010 \\
\hline $\mathrm{i} 17$ & c. $1879+5 \mathrm{G}>\mathrm{A}$ & Splicing defect & 0.03 & - & 1 & France & Lowe & This paper \\
\hline i17 & c.1880-5_1880-21del16 & p.Asn627fsX16 & & & 1 & Italy & Lowe & Addis et al., 2004 \\
\hline 18 & c. $1901 \mathrm{~T}>\mathrm{C}$ & p.Leu634Pro & & & 1 & \begin{tabular}{|l|} 
The Netherlands \\
\end{tabular} & Lowe & Böckenhauer et al., 2008 \\
\hline 18 & c.1923-1924delT & p.Ser642CysfsX4 & & & 1 & ni & Lowe & Böckenhauer et al., 2008 \\
\hline 18 & c.1925_1926delCT & p.Ser642CysfsX9 & & & 1 & North-America & Lowe & Lin et al., 1997 \\
\hline 18 & c.1927_1928delGT & p.Val643AsnfsX9 & 0.21 & $+/-$ & 1 & France & Lowe & This paper \\
\hline 18 & c. $1987 \mathrm{C}>\mathrm{T}$ & p.Arg663X & 0.04 & - & 5 & $\begin{array}{l}\text { North-America } \\
\text { Finland, France } \\
\end{array}$ & Lowe & $\begin{array}{l}\text { Lin et al., } 1997 \text {; Monnier et al., } 2000 \text {; } \\
\text { LSMD, } 2010\end{array}$ \\
\hline 18 & c. $2002 \mathrm{~T}>\mathrm{G}$ & p.Phe668Val & & & 1 & France & Lowe & Swan et al., 2010 \\
\hline 18 & c. $2071 \mathrm{~A}>\mathrm{T}$ & p.Lys691X & & & 2 & ni & Lowe & Böckenhauer et al., 2008 \\
\hline 18 & c.2071delA & p.Lys691LysfsX13 & & & 1 & France & Lowe & Monnier et al., 2000 \\
\hline 18 & c. $2083 \mathrm{C}>\mathrm{T}$ & p.Arg695X & & & 5 & $\begin{array}{l}\text { North-America } \\
\text { Kuweit, France } \\
\end{array}$ & Lowe & $\begin{array}{l}\text { Lin et al., } 1998 \text {; Monnier et al., } 2000 \text {; } \\
\text { Addis et al., } 2004\end{array}$ \\
\hline 18 & c. $2086 \mathrm{G}>\mathrm{T}$ & p.Glu696X & & & 1 & Belgium & Lowe & This paper \\
\hline 18 & c.2092delC & p.Pro698LeufsX66 & \multicolumn{3}{|c|}{ John Wiley \& Sфhs, Inc. } & Israel & Lowe & This paper \\
\hline
\end{tabular}




\section{Page 45 of 46}

19 c.2194dupC

19 c.2200delG

19 c.2203_2204insA

19 c. $2212 \mathrm{G}>\mathrm{C}$

19 c.2224_2226delGTA

\begin{tabular}{l|l|}
19 & c. $2244 \mathrm{C}>\mathrm{G}$ \\
\hline
\end{tabular}

i19 $\quad$ c. $2256+1 \mathrm{G}>\mathrm{A}$

\begin{tabular}{l|l}
20 & c. $2265 \mathrm{delG}$ \\
\hline
\end{tabular}

$20 \quad$ c. $2269 \mathrm{C}>\mathrm{T}$

20 c.2269delC

20 c. $2297 \mathrm{del} A$

\begin{tabular}{ll}
20 & c.2303T $>$ A \\
\hline
\end{tabular}

20 c.2311-2312insT

21 c.2341+1_del6

21 c.2360_2361delTG

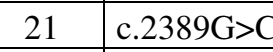

\begin{tabular}{lll}
21 & c. $2396 \mathrm{C}>\mathrm{T}$ \\
\hline
\end{tabular}

$21 \quad$ c. $2402 \mathrm{C}>\mathrm{T}$

\begin{tabular}{ll}
21 & c. $2415 \mathrm{C}>\mathrm{C}$ \\
\hline & $2 \mathrm{C}$ \\
\hline
\end{tabular}

\begin{tabular}{ll|l}
\hline 21 & c. $2416 \mathrm{G}>\mathrm{T}$
\end{tabular}

\begin{tabular}{l|l}
21 & c. $2428 \mathrm{C}>\mathrm{T}$ \\
\hline 21 & $\mathrm{c} .2433 \mathrm{~T}>\mathrm{A}$
\end{tabular}

$\begin{array}{lll}21 & \text { c. } 2433 \mathrm{~T}>\mathrm{A}\end{array}$

\begin{tabular}{ll|l}
\hline 21 & c. $2464 C>T$
\end{tabular}

\begin{tabular}{l|l}
21 & c. $2467 \mathrm{C}>\mathrm{T}$ \\
\hline & $\mathrm{c}$
\end{tabular}

\begin{tabular}{ll|l} 
i21 & c. $2469+2 \mathrm{~T}>\mathrm{G}$ \\
\hline
\end{tabular}

i21 c.2469+2_6delinsA

22 c.2470_2481del12

22 c.2515_2516insC

$22 \quad$ c. $2530 \mathrm{C}>\mathrm{T}$

\begin{tabular}{l|l}
\hline 22 & c. $2533 \mathrm{G}>\mathrm{T}$ \\
\hline
\end{tabular}

22 c.2550_2551insT

22 c.2553_7 del

22 c. $2581 \mathrm{G}>\mathrm{A}$

i22 $\quad$ c. $2581+1 \mathrm{G}>\mathrm{C}$

i22 $\quad$ c. $2581+4 \mathrm{~A}>\mathrm{G}$

i22 c. 2582-1G $>$ A

i22 c. $2582-2 \mathrm{~A}>\mathrm{G}$
p.Leu732ProfsX38 p.Val734PhefsX8 p.Pro735HisfsX35 p.Glu737Asp p.Val742del p.Tyr748X

Splicing defect

p.Leu755LeufsX70

p.Gln757X

p.Gln757ArgfsX68

p.Gln766fsX58

p.Ile768Asn

p.Cys771LeufsX8

Splicing defect

p.Val787GlyfsX2

p.Ala797Pro

p.Pro799Leu

p.Pro801Leu

p.Tyr805X

p.Glu806X

p.Arg810X

p.Cys811X

p.Arg822X

p.GIn823X

Splicing defect

Splicing defect

p.Val824_Gln27del

p.Leu839SerfsX12

p.Arg844X

p.Glu845X

p.Glu851X

p.Glu851GlufsX1

Splicing defect, p.Ala861Thr

Splicing defect

Splicing defect

Splicing defect

Splicing defect

\section{Human Mutation}

\begin{tabular}{|c|c|c|c|c|c|}
\hline & & 1 & UK & Lowe & This paper \\
\hline & & 1 & Belgium & Lowe & This paper \\
\hline & & 1 & North-America & Lowe & Lin et al., 1998 \\
\hline & & 1 & Italy & Dent-2 & Tosetto et al, 2009 \\
\hline & & 1 & Cuba & Lowe & This paper \\
\hline & & 1 & ni & Lowe & LSMD, 2010 \\
\hline & & 1 & Germany & Lowe & Keilhauer et al., 2007 \\
\hline & & 1 & Belgium & Lowe & Monnier et al., 2000 \\
\hline & & 1 & France & Lowe & This paper \\
\hline & & 1 & ni & Lowe & LSMD, 2010 \\
\hline & & 1 & Italy & Lowe & Addis et al., 2004 \\
\hline & & 1 & France & Lowe & Monnier et al., 2000 \\
\hline & & 2 & France, Mali & Lowe & This paper \\
\hline & & 1 & ni & Lowe & Böckenhauer et al., 2008 \\
\hline $0.10-0.16$ & - & 4 & $\begin{array}{l}\text { North-America, } \\
\text { India }\end{array}$ & Lowe & $\begin{array}{l}\text { Lin et al., } 1997 \text {; Lin et al., } 1998 \text {; this } \\
\text { paper }\end{array}$ \\
\hline 0.39 & ++ & 1 & France & Lowe & Monnier et al., 2000 \\
\hline 0.09 & ++ & 1 & France & Dent-2 & Swan et al., 2010 \\
\hline 0.22 & & 1 & France & Lowe & Swan et al., 2010 \\
\hline 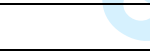 & 8 & 2 & France & Lowe & Monnier et al., 2000 ; this paper \\
\hline & & 1 & ni & Lowe & LSMD, 2010 \\
\hline 0.27 & & 5 & UK, India & Lowe & Monnier et al., 2000 ; this paper \\
\hline & & 1 & ni & Lowe & LSMD, 2010 \\
\hline & & $3 \longrightarrow 0$ & \begin{tabular}{|l|} 
Germany \\
Lebanon, ni
\end{tabular} & Lowe & This paper \\
\hline 0,05 & - & 1 & North-America & Lowe & Lin et al., 1998 \\
\hline 0.03 & & 1 & French & Lowe & This paper \\
\hline & & 1 & 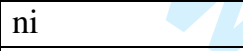 & Lowe & LSMD, 2010 \\
\hline & & 1 & North-America & Lowe & Leahey et al., 1993 \\
\hline & & 1 & ni & Lowe & LSMD, 2010 \\
\hline & & 4 & North-America & Lowe & Leahey et al., 1993 \\
\hline & & 1 & France & Lowe & Monnier et al., 2000 \\
\hline 0.07 & + & 1 & North-America & Lowe & Gropman et al., 2000 \\
\hline & & 1 & ni & Lowe & Böckenhauer et al., 2008 \\
\hline 0.14 & - & 10 & $\begin{array}{l}\text { Japan, Brasil, } \\
\text { Italy Belgium, } \\
\text { France, India }\end{array}$ & Lowe & $\begin{array}{l}\text { Kawano et al., } 1998 \text {; Monnier et al., } \\
2000 \text {; Addis et al., } 2004 \text {; Böckenhauer et } \\
\text { al., } 2008 \text {; LSMD, } 2010 \text {; this paper }\end{array}$ \\
\hline & & 1 & Spain & Lowe & This paper \\
\hline & & 1 & ni & Lowe & LSMD, 2010 \\
\hline & & 1 & Spain & Lowe & This paper \\
\hline$\theta$ & $y-8$ & 1 & India & Lowe & Sehti et al., 2008 \\
\hline
\end{tabular}




\begin{tabular}{|c|c|c|c|c|c|c|c|c|}
\hline 23 & c.2591_2595delTCACT & p.Phe864X & & & 1 & France & Lowe & This paper \\
\hline 23 & c. $2622 \mathrm{delC}$ & p.Asn874AsnfsX34 & 0.29 & & 2 & France, ni & Lowe & Satre et al., 1999 ; LSMD, 2010 \\
\hline 23 & c.2637_2638delGA & p.GIn879_Thr880>HisfsX4 & & & 1 & Grece & Lowe & This paper \\
\hline 23 & c.2642_2643insC & p.Pro881ProfsX2 & & & 1 & ni & Lowe & LSMD, 2010 \\
\hline 23 & c. $2672 \mathrm{~T}>\mathrm{G}$ & p.Leu891Arg & & & 1 & Maroco & Lowe & This paper \\
\hline $1-3$ & del exons $1-3$ & Genomic deletion, frameshift & & & 1 & France & Lowe & Monnier et al., 2000 \\
\hline $1-4$ & del exons $1-4$ & Genomic deletion, frameshift & & & 1 & France & Lowe & Monnier et al., 2000 \\
\hline $3-4$ & del exon 3-4 & Genomic deletion, frameshift & & & 1 & France & Dent-2 & This paper \\
\hline $6-12$ & del exons 6-12 & Genomic deletion, frameshift & & & 2 & North-America & Lowe & LSMD, 2010 \\
\hline $8-12$ & del exons 8-12 & Genomic deletion & & & 1 & Belgium & Lowe & Monnier et al., 2000 \\
\hline 14 & del exon 14 & Genomic deletion, frameshift & 0,10 & - & 1 & North-America & Lowe & Lin et al., 1997 \\
\hline $19-23$ & del exons $19-23$ & Genomic deletion, frameshift & 0,19 & & 1 & Canada & Lowe & This paper \\
\hline $1-23$ & del OCRL & Genomic deletion, & & & 2 & Australia, Italy & Lowe & Peverall et al., 2000 ; Addis et al., 2007 \\
\hline
\end{tabular}

\section{Supplementary Table S3 : Reported mutations in the OCRL1 gene}

${ }^{a}$ Numbering was based on the cDNA sequence (\#NM_000276) wih +1 corresponding to the A of the ATG initiation codon of translation in the reference sequence.

${ }^{\mathrm{b}}$ Expected consequences of the mutations with codon 1 corresponding to the ATG initiation codon of translation.

${ }^{c}$ The enzyme activities were normalized versus the normal activity values indicated by the different authors with 1 being the normal average value measured in controls.

When 2 or more patients have been tested for enzyme activity, extreme values are indicated.

${ }^{\mathrm{d}}$ The amount of OCRL1 present in patients' fibroblasts was estimated by western blot with ++++ indicating a normal amount and - a complete absence of the protein.

${ }^{\mathrm{e}}$ Total number of independent patients reported with the specific mutation.

${ }^{\mathrm{f}}$ ni: geographical origin of the patient not indicated 